\title{
GIS-based urban energy modelling and energy efficiency scenarios using the energy performance certificate database
}

\author{
Guglielmina Mutani (D) Valeria Todeschi $\mathbb{C}$
}

Received: 29 October 2020 / Accepted: 4 May 2021 / Published online: 31 May 2021

(C) The Author(s) 2021

\begin{abstract}
The EU building stock is 97\% not energy efficient and the promotion of energy retrofitting strategies is a key way of reducing energy consumptions and greenhouse gas emission. In order to improve the energy performance of buildings, the European Union released the Energy Performance of Buildings and the Energy Efficiency Directives. The certification of the energy performance of a building is a central element of these Directives to monitor and promote energy performance improvements in buildings, with the aim of increasing their energy efficiency level, thereby reducing greenhouse gas emissions. This work evaluates the energy performance of existing residential buildings using the energy performance certificate database and identifies the more effective retrofitting interventions by applying an urban-scale energy model. The novelty of this study is that a new retrofitting database is created to improve the results
\end{abstract}

Additional information: Improving energy efficiency in commercial buildings and smart communities

\section{G. Mutani $(\bowtie)$}

Department of Energy - Responsible Risk Resilience

Centre R3C, Politecnico Di Torino, Corso Duca degli

Abruzzi 24, Torino, Italy

e-mail: guglielmina.mutani@polito.it

\section{Todeschi}

Department of Energy - Future Urban Legacy Lab FULL, Politecnico Di Torino, Corso Duca degli Abruzzi 24,

Torino, Italy

e-mail: valeria.todeschi@polito.it of a building energy model at urban scale taking into account the real characteristics of the built environment. The here presented GIS-based monthly engineering model is flexible and easily applicable to different contexts, and was used to investigate energy efficiency scenarios by evaluating their effects of city scale. An urban energy atlas was designed for an Italian city, Turin, as a decision-making platform for policy makers and citizens. This energy platform can give information on energy consumption, production and productivity potential, but also on energy retrofitting scenarios. The results of this work show that it is possible to obtain energy savings for space heating of 79,064 MWh/year for the residential buildings connected to the district heating network in the city of Turin; these interventions refer mainly to thermal insulation of buildings envelope with windows replacement and allow a reduction in greenhouse gas emissions of 12,097 tonCO $\mathrm{CO}_{2 \mathrm{eq}}$ /year.

Keywords Urban energy simulation · GIS-based engineering model $\cdot$ Energy efficiency $\cdot$ District scale $\cdot$ Energy savings $\cdot$ Retrofitting interventions · Residential buildings

\section{Introduction}

The reduction of energy consumption in buildings is a fundamental point in the European Union policies aimed at achieving energy and climate targets, 
and the promotion of energy efficiency (EE) is one of the main priorities of the Energy Union. The civil sector is the most important energy consumer in the EU, with $97 \%$ of the EU building stock not being energy efficient and only $0.2 \%$ of EU residential buildings having undergone important retrofitting measures (Own-initiative procedure 2020/2070 INI 'Maximising the EE potential of the EU building stock'). In 2014, the European Council adopted new targets for 2030 in which they promoting renewable energy sources (RESs) and EE: reduced greenhouse gas (GHG) emissions by at least $40 \%$, increased use of RES by at least $32 \%$ and improved EE by at least $32.5 \%$. At a global level, the use of RES, combined with $\mathrm{EE}$ and electrification, is important for the world to meet the key climate goals by 2050. According to an IRENA report (International Renewable Energy Agency-IRENA, 2019), energy-related GHG emission reductions would have to decline by as much as $70 \%$ by 2050 , compared to the current levels, in order to reach the climate targets.

European Directives have introduced several instruments and tools to help achieve these targets (Papadopoulos, 2016; Serrano et al., 2017; Thomas \& Rosenow, 2020). The energy performance certificate (EPC) scheme was introduced, with Energy Performance Building Directive 2002/91/EC of December $16^{\text {th }}, 2002$, as a mandatory national scheme for both new buildings and some categories of already existing ones. An EPC scheme has the aim of monitoring and promoting energy performance (EP) improvements in buildings, by increasing the EE and reducing the GHG emissions of such buildings (Bio Intelligence Service et al., 2013; Bull et al., 2012).

The scope and implementation details of the EPC scheme vary significantly from EU country to country (Arcipowska et al., 2014). Italy introduced energy certification in 2005 with Legislative Decree no. 192 of August $9^{\text {th }}, 2005$, on the 'Implementation of Directive 2002/91/EC' related to the EP of buildings. In line with the EU directive (Economidou et al., 2020), Italian legislation has adapted its EE and consumption reduction goals to European Directive EPBD 2002/91/EC. The Italian Decree introduces a number of elements, such as the minimum requirements regarding the EP of buildings and mandatory energy certification to manage energy consumption and increase EE. Article 6 on 'Energy performance certificate, release and posting' introduces certification for existing and new buildings to improve their EP. EPC — which in Italy is called 'APE' (Attestato di Prestazione Energetica) - certifies the EP of a building on the basis of its energy class, from $\mathrm{A}+$ (more efficient) to $\mathrm{G}$ (less efficient). On October $1^{\text {st }}, 2015$, a new APE replaced the former certificate, and one of the novelties concerns the introduction of 10 energy classes (there were only 8 classes before October $1^{\text {st }}$, 2015). The energy class is supplied together with a numeric value that indicates the energy consumption expressed in $\mathrm{kWh} / \mathrm{m}^{2} /$ year. APE includes information on heating and cooling systems, domestic hot water production and ventilation. EPC generally gives information on energy consumption and the possibilities of reducing it through EE measures (Beerepoot \& Sunikka, 2005; Cerin et al., 2014; Davis et al., 2015).

$\mathrm{EPC}$ is also an information instrument for the owner or buyer of a building, when a building is sold, or of the tenant, in the case of leasing a property (Fregonara et al., 2014, 2017); in some cases, there is a positive correlation between EP and the property value of buildings. In Italy, since January $1^{\text {st }}, 2012$, APE has become mandatory when a house is put up for sale or for renting (i.e. renting a house out for more than 30 days, selling a new building, donating a house, and/or renovating a house by improving the energy performances). APE is also required to have access to tax incentives-in the form of eco-bonus (from 50 to $85 \%$ ) or super-bonus (110\%)-after retrofitting interventions. On June $10^{\text {th }}, 2020$, Legislative Decree no. 48, which amends Legislative Decree 192/2005, implemented EU Directive no. 844 of May $30^{\text {th }}, 2018$, on the Energy Performance of Buildings. The main changes that were introduced pertain to the calculation methodology that is adopted and the increase in sanctions in the case of buildings without any APE. Furthermore, the establishment of a national energy register, in which data should be collected related to the energy consumption of public and private buildings, was strongly recommended.

This work is organised as follows. The section 'State of the art' reports the literature review, research gap and the objectives of this study; 'Materials and method' describes the database, the methodology and the energy model at urban scale; 'Case study' presents the case study; the main results obtained from the application of the energy model and the investigated energy savings scenarios are presented in 'Results'; the last two sections ('Discussion' and 
'Conclusion') are related to the discussion and conclusions with a description of future developments.

\section{State of the art}

Urban-scale energy models (USEMs) are tools that are able to evaluate the distribution of the energy consumption of buildings at a city scale by applying energy saving scenarios (Sebi et al., 2019; Sola et al., 2018). Through an evaluation of the existing EE policies, it is possible to assess the effect of different energy retrofitting measures on improving the EP of buildings (Ben \& Steemers, 2020; Guelpa et al., 2018). Since USEMs take into consideration the real characteristics of an urban environment, they can be used to support territorial energy planning, through the promotion of a sustainable development of cities towards energy transition (Sola et al., 2019). Energy models and tools are currently available that use different approaches to simulate energy consumption at a territorial level, and their main limits concern the collection and availability of input data, their flexibility, the simulation times, and the accuracy of the simulations (Todeschi et al., 2021).

\section{Research background and gap}

Several studies (Cozza et al., 2020a, b; Cuerda et al., 2020; Moeller et al., 2020; Palma et al., 2019; Zou et al., 2018) have attempted to understand the discrepancy that exists between the simulated and real energy consumption of buildings. This discrepancy—called 'performance gap' — depends on several factors:

- Different approaches (i.e., top-down and bottomup) that can be used to assess the energy consumption of existing buildings according to the availability, accuracy, level and type of input data (Nouvel et al., 2017; Abbasabadi and Ashayeri, 2019). In some cases, USEMs consider the standard operating conditions instead of the real ones (Herrando et al., 2016). It is possible to have information from EPCs on the real characteristics of buildings, such as the EP, energy class, thermal properties of the envelope, and the energy saving after retrofitting measures (Semple and
Jenkins, 2020). Therefore, EPCs are a valid tool for improving energy simulations as they help to update the input data.

- It is possible to classify USEMs, according to the type of energy simulation, as: non-steady state models (Chalabi and Bailey, 1991) based on dynamic simulations, quasi-steady state models based on monthly or daily data sets (Corrado and Fabrizio, 2007) and steady-state models that do not consider the element of time (Veken et al., 2004). The time resolution can vary, from an hourly to annual precision, with different simulation times and different accuracy levels. With the existing tools, the more accurate the simulation is (e.g. hourly), the longer the analysis times. The here presented GIS-based models overcome this obstacle by simulating the energy consumption, with different time accuracies, through immediate simulations.

- Energy models can simulate the energy consumption, according to the analysis scale, at a building, neighborhood, district or city scale. One of the challenges of these models is connected to assess energy consumption at an urban scale, taking into consideration not only the building variables but also the surrounding urban context and the local climate conditions (Chen et al., 2017; Luo et al., 2020). According to the literature, different tools are available that are capable of running simulations at an urban level, such as CityBES, CitySim, UMI and SimStadt (Walter and Kämpf, 2015; Reinhart et al., 2013; Nouvel et al., 2017). The here presented GIS-based model is based on an urban thermal balance that uses urban parameters as input data to consider the effect of the urban environment on the EP of buildings.

Since it is possible to evaluate EE scenarios with USEMs, they can be considered fundamental tools to identify effective energy policies in order to promote a sustainable development of cities. The common goal of recent studies has been to provide information on the EE characteristics of the existing building stock considering retrofitting measures (Dall'O', 2012; Martínez-Molina et al., 2016; Streicher et al., 2019). Hjortling et al. (2017) assessed building energy consumption in Sweden with reference to 186,021 EPCs, and the authors identified the main 
energy-related variables, such as the type of users, the construction period and the climate zone. Droutsa et al. (2016) analysed 650,000 EPCs to understand the EP of existing residential buildings in Greece. They found that the most common retrofitting actions were the replacement of windows and the installation of solar collectors. Moreover, Ali et al. (2020a, b) proposed a methodology to identify retrofitting solutions by analysing a case study of Dublin. The authors investigated the EP of the building stock using an EPC dataset of the Irish residential stock. Cozza et al. (2020a, b) examined the performance gap of retrofitted buildings located in Switzerland using the Cantonal Energy Certificate for Buildings database. The authors analysed 1172 buildings for which both simulated and measured consumptions were known, and they found a gap of $-23 \%$ in the energy performance of building (pre-retrofitted); this gap became positive (2\%) for buildings that had been renovated. Ahern and Norton (2020) performed a similar analysis and found that, for Ireland's single-family housing, the adoption of thermal default values ( $U$-values) underestimated the energy performance of about $90 \%$ of the dwellings. The authors introduced a methodology, based on an Irish EPC database that is able to assess a realistic energy savings, after building retrofitting, using default $U$-values. Fan and Xia (2018) optimised building energy retrofitting models using the EPCs of a few buildings in South Africa. The optimisation was conducted using a grouping method and verifying the energy savings of the sample of retrofits. In general, the performance gap between predicted and measured energy use was found to deviate by $34 \%$, and to depend on the model approach (impact of $20-60 \%$ on energy use), occupant behaviour (impact of 10-80\%), and poor operational practices (impact of 15-80\%) (van Dronkelaar et al., 2016).

Many studies have used a Geographic Information System (GIS) to assess the EP of buildings at an urban scale (Barrile et al., 2018; Fabbri et al., 2012; Groppi et al., 2018; Gupta \& Gregg, 2018; Quan et al., 2015; Yang et al., 2020). Ali et al. (2020a, b) introduced a bottom-up approach, based on an EPC database of residential buildings in Ireland, using GIS tools. They designed a tool for multi-scale GIS-based building energy modelling - from the individual building level to the national level - to analyse, plan and support decision-making. Dall'O' et al. (2012) used tools in a GIS platform to assess the EP of buildings, and they presented a method to assess the EP of buildings located in the Lombardy Region (Italy) at a local and regional level. Caputo and Pasetti (2017) introduced a GIS-based tool to promote the energy retrofitting of the private building stock in Italy using EPCs. Therefore, a GIS platform (i.e., energy atlas) offers a tool that can be used to model, organise, manage and evaluate the EP of building at a territorial level. Such an 'energy atlas' is generally used to describe the distribution of energy consumption at a territorial level, from a building to a city scale, and to analyse the retrofitting level of buildings and the potential energy savings (Johansson et al., 2017a, b; Kristensen et al., 2018; Mutani \& Todeschi, 2019; Perera et al., 2018; Petrović \& Karlsson, 2016). This tool is also able to calculate the energy that can be produced from the available RES (e.g. solar photovoltaic panels and thermal collectors) (Alhamwi et al., 2017; Ashfaq \& Ianakiev, 2018). The urban energy atlas presented in this work is a decision-making tool, based on USEMs, that is able to visualise and map data, but also to predict phenomena thanks to the engineering approach that has been incorporated.

It has emerged, from the research background, that having information available on the EP of buildings at a district or city scale is important to effectively identify energy planning strategies. The aim is to pilot the retrofitting strategies of buildings in order to reach certain energy and climate targets. The use of GIS tools is fundamental to manage an EPC database and to evaluate the impact of $\mathrm{EE}$ measures on the basis of the real characteristics of the buildings.

\section{Research objectives}

This work presents an assessment of an EPC database of the Piedmont Region (Italy), an input data optimisation of a monthly engineering model that simulates the energy consumption of buildings at a district level, and an updating of a GIS-based urban energy atlas designed for the city of Turin (Italy) (Mutani \& Todeschi, 2019). The aim is to promote the sustainable development of cities by defining potential retrofitting strategies according to: the EPC database, the distribution of space heating $(\mathrm{H})$ and domestic hot water (DHW) consumptions, and the real characteristics of the built-up environment. This urban energy atlas is based on a GIS-based model, which uses a top-down engineering approach, with monthly 
details according to the Italian UNI/TS 11,300 standard (Mutani \& Todeschi, 2020). The place-based tool gives information on (i) the characteristics of the building stocks, such as the number of floors, the heated volume, the surface-to-volume $(S / V)$ ratio, the construction period and the type of users; (ii) the built-up environments, such as the building coverage ratio $(B C R)$, the building density $(B D)$, the canyon height-to-width effect $(H / W)$ ratio and the normalised difference vegetation index $(N D V I)$; (iii) the distribution of residential energy consumption for $\mathrm{H}$ and DHW, according to the building typologies and local climate conditions; (iv) the local availability and/or feasibility of RES (i.e., solar, wind, biomass), taking into consideration the existing constraints and natural limits; (v) the indoor and outdoor thermal comfort conditions. Therefore, such a place-based tool is able to visualise the distribution of energy consumption at different territorial scales, assess the constraints and limits on a territory and evaluate the potential energy savings and/or EE measures that boost the available RES. It is a decision-making tool and provides useful information for policy makers, urban planners and citizens. The use of RES should be supported in favourable areas, by introducing appropriate policies and strategies, and using smart green technologies. Since EPC is a useful tool to obtain information on energy consumption and, consequently, to find solutions that can improve the EP of buildings (Mutani et al., 2020a), the presented work investigates some EE scenarios for low-carbon cities using the EPC database of the Piedmont Region.

The main objectives of this paper can be summarised as follows:

- This work presents not only an assessment of the EP of buildings using the EPC database, but also improves the simulation accuracy of an engineering model by updating the input data. The model simulates $\mathrm{H}$ and DHW consumption at an urban scale, with monthly details, considering the real characteristics of the buildings and their surroundings. The electricity consumption is not calculated, since the models used to simulate electricity consumption are of a different type and require other kinds of input data (i.e., number of families, per capita income); these kinds of models will be investigated in future works.
- The here presented urban energy atlas uses a GISmapping tool, gives information on EE trends, and creates energy consumption and energy saving maps of buildings at different territorial scales, for both individual buildings and aggregated data. This update has been possible thanks to the use of GIS tools and to the flexibility of the methodology. The GIS-based engineering model mainly uses open data, and it is possible to easily apply it to different cities. The impact of EE measures on the EP of buildings can easily be assessed by integrating the atlas with an EPC database and applying energy models.

- An in-depth analysis of the energy retrofitting of buildings provides possible low-carbon emission energy scenarios for a more resilient and sustainable city. The reduction in energy consumption and, consequently, in GHG emission has been assessed.

\section{Materials and method}

Since an EPC scheme is an important tool to support $\mathrm{EE}$ in buildings and to give information on the EP of a building, an EPC database has been used in this work to identify retrofitting scenarios for residential buildings, to improve the input data of a GIS-based energy model and to update an energy atlas by creating a new retrofitting database. Figure 1 shows the main steps of this work:

1. Analysis of the EPC database. The EPC database of residential buildings in the Piedmont Region has been processed and elaborated to support energy retrofitting strategies and to assess the EP of buildings (Mutani et al., 2020a). After the acquisition and analysis of the EPC, homogenous groups were identified. The residential buildings were classified as flats or detached houses using the $S / V$ ratio. Since the main characteristics of a building depend on the construction period, eight classes of buildings were created. Three databases were created according to the motivation for the release of the EPC: generic for existing buildings, retrofit for retrofitted buildings and Res for buildings that have undergone the installation of renewable energy technologies. The EP of residential buildings and the energy savings 


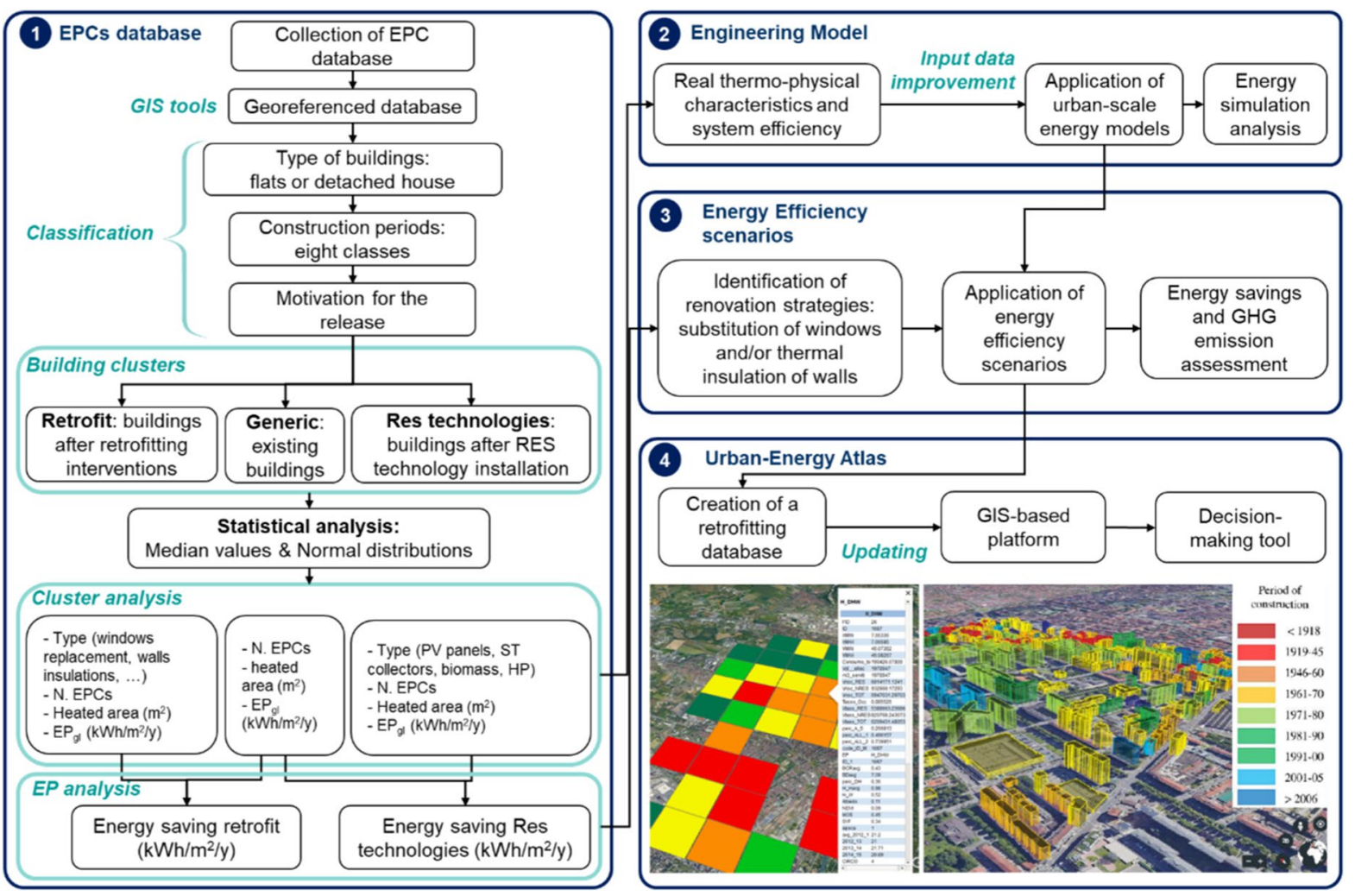

Fig. 1 Flowchart of the methodology: EPC database processing, engineering model application, identification of energy efficiency scenarios, and urban energy atlas updates as a decision-making tool

were calculated, for each homogenous group, on the basis of the retrofitting intervention and the installation of renewable energy technologies.

2. Input data improvement of an existing monthly engineering model, using the real characteristics of buildings. An existing GIS-based monthly engineering model (Mutani \& Todeschi, 2020) was updated to assess residential energy consumption at different territorial scales, using real input data of the thermal transmittance values of the opaque envelope $\left(U_{o p}\right.$, $\left.\mathrm{W} / \mathrm{m}^{2} / \mathrm{K}\right)$ and glazing $\left(U_{g}, \mathrm{~W} / \mathrm{m}^{2} / \mathrm{K}\right)$ of the buildings, and the space heating $\left(\eta_{H},-\right)$ and domestic hot water $\left(\eta_{D H W},-\right)$ system efficiency. The thermal transmittance values and system efficiencies in the first version of the engineering model referred to literature reviews and Italian standards (standard operating conditions) and did not take into account the share of retrofitted buildings. Therefore, the accuracy of the previous model has been improved using new input variables $\left(U_{o p}, U_{g}, \eta_{H}\right.$ and $\left.\eta_{D H W}\right)$ that are the result of EPC data processing.
3. Identification of EE scenarios. EE assumptions were made considering the most frequently used energy retrofitting measures. The thermal consumption was simulated, before and after the use of $\mathrm{EE}$ measures, for non-retrofitted residential buildings, to assess the energy and environmental impacts.

4. Implementation of an existing urban energy atlas of the city of Turin (Mutani \& Todeschi, 2019) which is able to map and visualise, for example, the energy retrofitting trends-with the EPC database of residential buildings. The main information that was added was: the energy label, EP, and the reachable EP of residential buildings, the used energy retrofitting measures, and presence of RES technologies.

The subsections presented below describe the four main steps of this work: the analysis of the EPC database (section 'Energy Performance Certificate database'), the updating of the top-down monthly 
engineering model (section 'Monthly engineering model'), the identification of EE scenarios for residential buildings (section 'Energy Efficiency scenarios') and the implementation of the urban energy atlas of Turin (section 'Urban energy atlas').

Energy performance certificate database

In the first phase of this work, the EPC database was georeferenced and elaborated with GIS tools. The analysed database was composed of over 55,000 certificates of which $75 \%$ referred to buildings served by the district heating network (DHN). The data were processed using a statistical analysis to discard any anomalous data, and the certificates of residential building were grouped into clusters to identify EE measures according to the type of retrofitting interventions and to the installation of renewable energy technologies. Starting from previous research (Mutani \& Todeschi, 2020; Mutani et al., 2020a), the EPC database was used to improve the accuracy simulation of two monthly USEMs (the 'H+DWH' model and ' $\mathrm{H}$ ' model) and to update an existing urban energy atlas of the city.

This section describes the information obtained from the EPCs and the methodology used to process and elaborate such information. EPCs give information on the annual energy demand, including the energy requirements (energy label), and recommendations to improve EP. The main data contained in the EPCs used to elaborate the database refer to: coordinates, address, type of users, geometrical characteristics (i.e., $S / V$ ratio and net heated area), construction period, motivation for the EPC release, $\mathrm{EP}$ and the energy label. Coordinates and addresses were used to georeference the database in the GIS; the type of users, the geometrical characteristics and the construction period were the main energy-related variables used to identify the building clusters, while the motivation for the release of an EPC was considered to assess each cluster; EP and the energy label were used to analyse the EP of the buildings of each cluster. The procedure used to process the database and discard the anomalous data, which had already been tested in a previous work (Mutani et al., 2020a), is based on median values of EP intensity $(\mathrm{kWh} /$ $\mathrm{m}^{2} /$ year) for each type of building and homogeneous group of EPCs. In addition, the normal distributions of the EP values, $U_{o p}, U_{g}, \eta_{H}$ and $\eta_{D H W}$, were produced in order to implement the statistical analysis. Such processing data is in fact fundamental; it has emerged from the literature (Hardy \& Glew, 2019; Hjortling et al., 2017; Las-Heras-Casas et al., 2018) that, in order to describe the building stock, EPC databases have to be corrected by improving the accuracy and quality of the data. The following five steps were used to process the EPC database:

- Acquisition and analysis of the EPCs. EPCs from the regional database-from November 2009 to September 2015-pertaining to the city of Turin and to the area served by the DHN were georeferenced using information on the coordinates and the addresses indicated in the certificates. The EPCs were then classified according to the type of users. The following eight categories were considered in the EPCs:

- E.1 (1) residential buildings used as permanent residences

- E.1 (2) residential buildings used for residence with occasional occupation

- E.1 (3) buildings used as hotels or similar activities

- E.2 buildings used as offices or similar activities

- E.3 hospitals, nursing homes and clinics

- E.4 buildings used for recreational, associative or religious activities or similar

- E.5 Buildings used for commercial activities

- E.6 buildings used for sports activities

- E.7 buildings used for school activities

- E.8 industrial buildings heated for the comfort of the occupants (according to Italian Decree 412/93)

The EPCs investigated in this work only referred to buildings used as residences or similar, that is, the E.1 (1) and E.1 (2) categories.

- Classification of the type of residential buildings. The considered residential buildings were classified as flats or detached houses, to differentiate between the building typologies, using the $S / V$ values. The $S / V$ ratio was indicated in the EPCs and it was also calculated by means of GIS tools for verification purposes. Most of the EPCs located 
in the city were flats in condominiums $(96.8 \%$ in Turin).

- Classification of the construction period. Eight classes were identified considering the construction period of the residential buildings: before 1918, 1919-1945, 1946-1960, 1961-1970, 19711980, 1981-1990, 1991-2005 and after 2006. The main characteristics of the buildings, which depend on the period of construction, are: the level of thermal insulation of the opaque and transparent envelopes ( $U$-values), the type of envelope and the efficiency $(\eta)$ of the energy systems.

- Classification of the motivation for the release of the EPCs. The following motivations are indicated in the certificates: change of ownership, renting or other, new building, sale announcement, energy retrofitting, building renovation, important retrofitting activity, usability request, change in energy performance, extension in derogation (LR 20/2009), loan for use, usufruct and energy service contract. The motivation for the release was used to assess the EP of existing buildings (called 'generic') and those of retrofitted buildings (called 'retrofit') or after the installation of renewable energy source technologies (called 'Res'). Three databases were identified according to this classification: generic, retrofit and Res. The EPCs with renewable energy technologies were also selected by checking the type of technological systems and the energy production data from RES.

- Statistical analysis. After the creation of the building clusters, any anomalous data in each group were discarded using the median values. In addition, in order to evaluate the frequency distribution of the values (i.e., EP), the normal distributions were evaluated. Two statistical tests were run conjunction with the distributions to observe the trend of the EP of the buildings, the thermal transmittances, and of the system efficiency value data, as well as to identify any anomalous data: the Kolmogorov-Smirnov $(K S)$ and chi-squared $\left(\chi^{2}\right)$ tests. Therefore, the following data, which are typical of each cluster, were identified in this phase, for the three databases (generic, retrofit, Res) according to the eight construction periods: $\mathrm{EP}, U_{o p}, U_{g}, \eta_{H}$ and $\eta_{D H W}$ (distinguishing between the generic, retrofit and Res databases).

- Analysis of the annual consumptions. The EPCs were subdivided into homogeneous groups (only residential users) by means of the previous steps, according to the typology of the building (flat or detached house), the construction period, and the motivation for the release of the EPCs. The EP of residential buildings was evaluated using the $E P_{g l}$ index, expressed in $\mathrm{kWh} / \mathrm{m}^{2} /$ year, by considering the energy consumption for $\mathrm{H}$ and DHW. The annual energy performance $E P_{g l}\left(E P_{\text {gl,generic }}\right.$, $\left.E P_{\text {gl, retrofit }}, E P_{g l, R e s}\right)$, the reachable energy performance $E P_{g l \text {,reach }}$ and the annual energy savings $\left(E_{\text {savings }}\right)$ after retrofitting measures and/or after the installation of RES technologies were evaluated for each group of EPCs (generic, retrofit and Res). Once the amount of net heated area $\left(\mathrm{m}^{2}\right)$ of the residential buildings (which is indicated in the EPCs) was known, it was possible to calculate the global consumption of the building ( $\mathrm{kWh} /$ year) from the EP.

The equations presented below show the methodology used to calculate the current annual energy saving trends after retrofitting measures ( $E_{\text {savings, retrofit }}$ Eq. 1a) and after the installation of RES technologies ( $E_{\text {savings, res, }}$ Eq. 1b):

$E_{\text {savings,retrofit }}=E P_{\text {gl,generic }}-E P_{\text {gl,retrofit }}$

$E_{\text {savings,res }}=E P_{\text {gl,generic }}-E P_{\text {gl,Res }}$

where.

- $E P_{\text {gl,generic }}\left(\mathrm{kWh} / \mathrm{m}^{2} / \mathrm{y}\right)$ is the EP of a building without any energy retrofitting interventions or the installation of RES technologies elaborated according to the generic database.

- $E P_{\text {gl, retrofit }}\left(\mathrm{kWh} / \mathrm{m}^{2} / \mathrm{y}\right)$ is the EP of a building after retrofitting interventions elaborated according to the retrofit database.

- $E P_{g l, R e s}\left(\mathrm{kWh} / \mathrm{m}^{2} / \mathrm{y}\right)$ is the EP of a building after the installation of RES technologies elaborated according to the Res database.

The EPCs were grouped according to the type of intervention, and the reachable $E P_{g l}\left(\mathrm{kWh} / \mathrm{m}^{2} / \mathrm{y}\right)$ indicator was used to quantify the energy savings (Eq. 2).

$E_{\text {savings,int }}=E P_{\text {gl,int }}-E P_{\text {gl, reach, }, \text { int }}$

where. 
- $E P_{\text {gl,int }}\left(\mathrm{kWh} / \mathrm{m}^{2} / \mathrm{y}\right)$ is the EP of a building after specific energy retrofitting interventions or the installation of RES technologies elaborated according to the generic database.

- $E P_{\text {gl, reach,int }}\left(\mathrm{kWh} / \mathrm{m}^{2} / \mathrm{y}\right)$ is the EP calculated by the certifiers, which indicates the feasible interventions, from a technical, historical, environmental and an economic point of view (only the interventions with a payback time lower than 10 years were indicated in the EPCs used for the calculation of $\left.E P_{\text {gl, reach }}\right)$.

\section{Monthly engineering model}

As previous mentioned, this study proposes an improvement in the input data of an engineering model at an urban scale, and investigates EE scenarios as taken from an EPC database. Energy consumptions for the space heating $(\mathrm{H})$ and domestic hot water (DHW) of residential buildings, with monthly details, were simulated at a district level $\left(1 \mathrm{~km}^{2}\right.$ mesh) for three consecutive heating seasons (2012/2013, 2013/2014 and 2014/2015). The existing urban-scale energy models for $\mathrm{H}+\mathrm{DHW}$ and $\mathrm{H}$ were optimised using new $U$-vales and $\eta$-values elaborated from an EPC database (2009-2015).

The presented GIS-based engineering model was based on a thermal balance at an urban scale. The $\mathrm{H}$ and DHW consumptions of residential buildings served by the DHN were simulated for a $1 \mathrm{~km} \times 1 \mathrm{~km}$ mesh. In a previous work (Mutani \& Todeschi, 2019, 2020), the model was validated using the real energy consumption of three consecutive heating seasons (2012/2013, 2013/2014 and 2014/2015). The measured consumption data for $\mathrm{H}$ and DHW were aggregated data and referred to residential users located in $1 \mathrm{~km} \times 1 \mathrm{~km}$ meshes. For this reason, the engineering model was designed according to this scale, but being flexible, it can also be applied to the building scale or the entire city (Todeschi et al., 2021). The model was designed according to the ISO EN 52,016-1:2017 and ISO EN 52,017-1:2017 standards for residential buildings, and the main input data, elaborated with GIS tools (ArcGIS, ESRI) at building and district scales, were indicated as follows:

- Building data: type of user, construction period, maintenance level, net/gross heated area, net/gross heated volume, internal building air temperature $\left(T_{a i},{ }^{\circ} \mathrm{C}\right), U$-values of the opaque envelope and glazing $\left(\mathrm{W} / \mathrm{m}^{2} / \mathrm{K}\right)$, compactness or $S / V\left(\mathrm{~m}^{2} / \mathrm{m}^{3}\right)$ ratio, and $\eta(-)$. Some new input building data were calculated at a district scale ( $U$-values and $\eta$-values) from the EPC database to improve the simulation accuracy.

- Local climate data: air temperature $\left(T_{a e},{ }^{\circ} \mathrm{C}\right)$ and relative humidity $(U R, \%)$, solar irradiance $\left(I_{\text {sol }}\right.$, $\left.\mathrm{W} / \mathrm{m}^{2}\right)$ and heating degree days $\left(H D D,{ }^{\circ} \mathrm{C}\right)$.

- Urban parameters: the orientation of the main streets $(M O S,-)$, the sky view factor $(S V F,-)$, the relative height $\left(H / H_{\text {avg }}, \mathrm{m}^{2} / \mathrm{m}^{2}\right)$ and the canyon effect, which is described as the height-to-width $\left(H / W, \mathrm{~m}^{2} / \mathrm{m}^{2}\right)$ ratio. These parameters were calculated at an urban level for each mesh.

Equations 3, 4 and 5 show the energy balance for $\mathrm{H}$ and DHW consumption for each homogeneous group of buildings at an urban scale. The $\mathrm{H}$ energy demand was simulated by analysing the total heat transfer $\left(Q_{H, h t}\right)$ and the total heat gains $\left(Q_{g n}\right)$.

$Q_{H, n d}=Q_{H, h t}-Q_{g n}=\left(Q_{H, t r}+Q_{H, v e}\right)-\left(Q_{s o l}+Q_{i n t}\right)$

where.

- $Q_{H, t r}$ is the heat loss due to transmission, which was calculated as a function of: (i) the transmission heat transfer coefficient, considering $U$-values of the buildings, opaque and transparent heat dispersing areas, and unheated volumes of the attics and cellars; (ii) the extra heat transfer, considering the thermal radiation lost to the sky and the form factor between the building stock and the sky, which is described using the SVF (calculated at an urban level for each mesh).

In previous works, the $U$-values and $\eta$-values of buildings referred to the standard operating conditions instead of the real ones; in this work, real $U$ and $\eta$ data-taken from the EPCs database according to the construction period of the buildingswere used to improve the accuracy of the model.

- $Q_{H, v e}$ is the heat loss due to ventilation, which was calculated as a function of (i) the heat capacity of the air per volume (ii) and the air exchange volumes.

- $Q_{s o l}$ is the solar heat component, which was calculated as a function of (i) the incident solar irra- 
diance; (ii) the solar exposition; (iii) the shading reduction factor due to the external obstructions, which is described using the $S V F$; (iv) the total solar energy transmittance according to the construction periods.

In the first version of this model, MOS and the $H /$ $H_{\text {avg }}$ were used to take into account the influence of the incident solar irradiance (Mutani \& Todeschi, 2020). The model was then optimised by replacing $M O S$ and $H / H_{\text {avg }}$ with the solar height and $H / W$ ratio. The incident solar irradiance on the envelope was assessed considering the variation in the shadow percentage for each building as a function of the solar height and the aspect $H / W$ ratio (Mutani et al., 2020b).

- $Q_{i n t}$ is the internal heat component, which was calculated as a function of (i) the floor area (ii) and the average area per dwelling.

The energy demand for DHW $\left(Q_{D H W, n d}\right)$ was calculated according to Eq. 4:

$Q_{D H W, n d}=\rho_{\omega} \cdot c_{\omega} \cdot V_{\omega} \cdot\left(T_{e r i}-T_{o}\right) \cdot G$

where.

- $\rho_{\omega}$ and $C_{\omega}$ are the density and the specific heat of water

- $V_{\omega}$ is the required daily volume of hot water as a function of the average floor area per dwelling in each mesh, and for residential buildings

- $\left(T_{e r i}-T_{o}\right)$ is the difference between the hot water supply temperature (assumed equal to $40{ }^{\circ} \mathrm{C}$ ) and the incoming cold water temperature (assumed equal to the annual air temperature)

- $G$ is the number of days of the considered calculation period (year) which, in this case, was equal to 365 days.

The energy supplied for space heating $\left(Q_{H}\right)$ and domestic hot water $\left(Q_{D H W}\right)$ for each district was quantified using Eq. 5:

$Q=Q_{n d} / \eta$

where.

- $Q_{n d}$ is the required energy, calculated according to Eqs. $3\left(Q_{H}\right)$ and $4\left(Q_{D H W}\right)$
- $\eta$ is the annual average values of the system efficiencies for the heating $\left(\eta_{H}\right)$ and domestic hot water systems $\left(\eta_{D H W}\right)$, identified according to the construction periods, considering centralised systems connected to the DHN

In order to apply the urban balance, specific values of $U$ and $\eta$ were identified for each construction period, and an average value was given with each district $\left(1 \mathrm{~km}^{2}\right)$, considering the percentage distribution of the buildings with different construction periods and the quota of heated volume served by the DHN. The thermal transmittances of the opaque envelope $\left(U_{o p}\right)$ and glazing $\left(U_{g}\right)$, and the $\eta$-values were calculated from the EPC database of the city of Turin, according to the motivation for the release of the EPC (generic or retrofit). The median values of $U_{o p}, U_{g}$, $\eta_{H}$ and $\eta_{D H W}$ were then calculated for each mesh. The conversion factors for the energy supplied as primary energy from the Turin DH system were used.

\section{Energy efficiency scenarios}

In the third part of this work, EE scenarios were hypothesised considering the real characteristics of the existing building heritage. The following retrofitting measures were identified from an analysis of the EPC database (retrofit) of the city:

- Installation of thermostatic valves

- Thermal insulation of the roof

- Thermal insulation of the slab and/or floor

- Replacement of windows

- Thermal insulation of the opaque envelope and window replacement

Once the most common retrofitting measures were known, and the real characteristics of the buildings were taken into account, EE scenarios were hypothesized. In this work, two energy efficiency scenarios were applied for each mesh in the district heating area: (i) thermal insulation of the opaque envelope (ii) and thermal insulation of the opaque envelope and window replacements. The monthly energy models were used to evaluate the $\mathrm{H}$ and DHW consumptions before and after the energy retrofitting of the residential buildings. The energy savings and GHG emission reductions were assessed for each mesh. Furthermore, 
an analysis on the cost implications of retrofitting measures was carried out.

\section{Urban energy atlas}

An urban energy atlas of the city of Turin was created in a previous work (Mutani \& Todeschi, 2019) using Google Earth and GIS tools. With this web tool, it is possible to explore-at different scales-energy consumption, production and productivity and to evaluate how energy consumption changes according to the various levels of building EE. Through the combined use of energy consumption, production and productivity models, it is possible to evaluate low-carbon scenarios in which energy security is improved for a more sustainable city.

A new and more complete database of the city of Turin has been created in this work. The retrofitting database has been organised in GIS using information on EPC data, and this allows the retrofitting interventions that have actually been carried out to be evaluated, thus taking into account all the technological, economic and environmental limits that have been considered in the city. Future EE scenarios have been hypothesised taking into consideration the most popular retrofitting actions, such as the thermal insulation of the building envelope and/or window replacements. The monthly energy savings have been quantified through the use of USMEs. Figure 2 shows some outputs of the urban energy atlas that represent the real characteristics of the built environment and its EPs.

This platform is a decision-making tool, rather than just a mapping tool or a static atlas. It is an interactive platform and allows the impacts of possible EE scenarios that are applied considering the real physical, economic, environmental and technical characteristics of the buildings to be evaluated. It should help stakeholders, urban planners and policy makers to plan sustainable cities and smart energy systems. This web-platform provides real information on the distribution of the retrofitting measures of existing residential buildings. Through the use of a GIS-based approach, and overlying building data with environmental, economic and social data, it is possible to implement energy retrofitting strategies at a city level and to identify critical areas that require higher priority interventions.

\section{Case study}

This section describes a case study of the city of Turin (Italy). The city has a temperate Mediterranean climate and a population of 866,425 (updated on 31 August 2020). There are 60,000 heated buildings, of which 45,000 are residential buildings. The residential sector is principally made up of large and compact condominiums with an $S / V$ ratio of less than $0.45 \mathrm{~m}^{2} / \mathrm{m}^{3}$, and $80 \%$ of the buildings were built before the first Italian Law on Energy Efficiency (1976). A total of 182,718 EPCs, registered from 2009 to 2015, for Turin were selected from a regional database, of which 55,276 are located in the 33 districts analysed in this work, $(41,848$ are served by the DHN). Considering the building typology, 54,747 EPCs refer
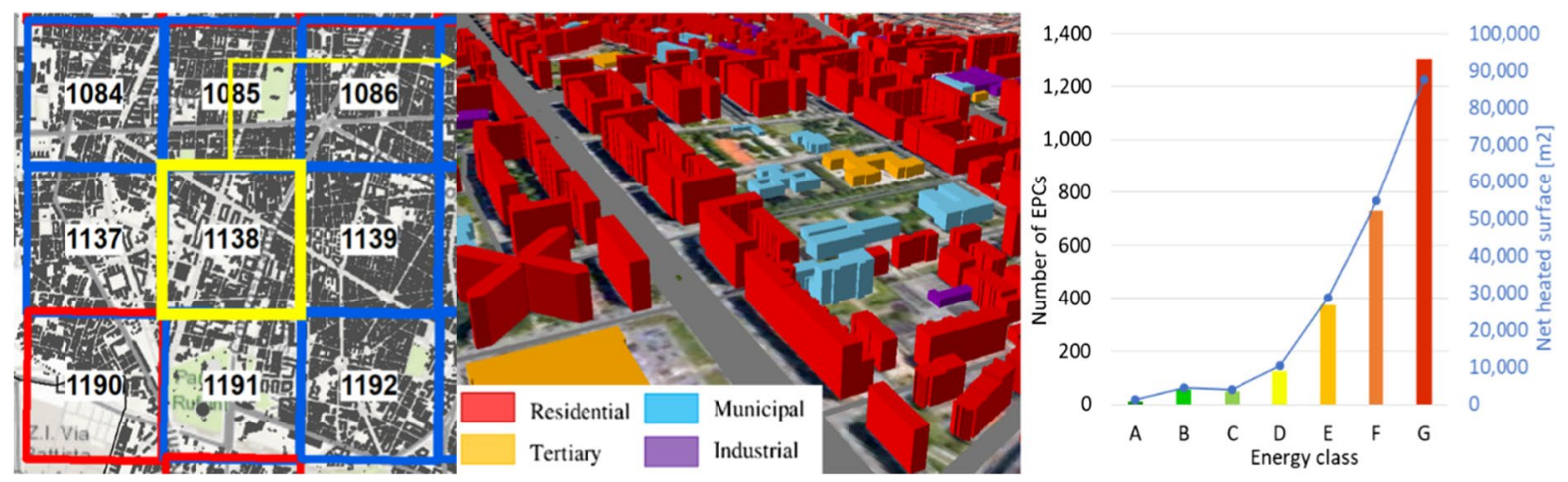

Fig. 2 Example of some aspects of the urban energy atlas: mesh identification; building classification according to the type of user; EPC data of the residential sector 
to flats (of which 41,709 are served by DHN) and only 529 EPCs refer to detached houses (of which 139 are served by the DH network).

Table 1 shows the number of EPCs, according to the generic, retrofit and Res typologies, for the flats and detached houses. It is possible to observe that the 33 districts selected for the analysis of this work reflect the average characteristics of the whole city. The number of certificates (see the percentages) of the 33 districts was very close to that of the city of Turin, and the EPs of the buildings covered by the 33 districts, as characterised by their EPCs, were therefore statistically representative of the whole building stock of the entire city of Turin. Moreover, the quota of retrofitted buildings is particularly low, and to reach the European energy and climate targets it would be necessary to promote EE in buildings through the use of new financial instruments and already existing incentives (Bertoldi et al., 2020).

Figure 3 shows the part of Turin considered in the case study and differentiates between the buildings according to the Municipal Technical Map of the city, with the 33 meshes served by the DH network $(1 \mathrm{~km} \times 1 \mathrm{~km}$ meshes) and the distribution of the EPCs. The colour of the mesh outline specifies homogeneous groups of residential buildings, on the basis of the measured DH energy consumption types $(\mathrm{H}+\mathrm{DHW}$ in blue or $\mathrm{H}$ in red). The number of EPCs in each district (33 meshes) is very important in this work because the thermo-physical characteristics of the buildings and the efficiency of the systems have been calculated for each mesh on the basis of EPC information. The calculated $U$-values and $\eta$-values were found to be more accurate where there was a large number of EPCs, for example, in the mesh numbers $981,1085,1087$ and 1192.

In order to discard any anomalous data from the EPC database and assess the distributions of data, the median values and normal distributions of the EP of the buildings and the $U_{o p}, U_{g}$ and $\eta$-values were analysed. The normal distributions were only elaborated for the flats since the detached houses did not have a sufficient number of EPCs. Figure 4 shows an example of the normal distributions for flats built before 1919, according to the generic database: the $U_{o p}$ and $\eta H$ values are indicated. $K S$ was verified for the $U$-values and both $K S$ and $\chi^{2}$ tests were run for the $\eta$-values. It has emerged, from the generic database, that most of the residential buildings were built before 1970 (69\%), and the new buildings built after 2005 only represent a small percentage, that is, $2 \%$. A total of $93 \%$ of the retrofit EPCs refer to buildings built before 1970, and this is because there are only a few new buildings that do not need to be retrofitted. The limited number of EPCs for some construction periods does not allow a reliable identification of all the buildings to be made, in particular for those built after 2005. This aspect does not limit the application of the models, as most of the buildings in Turin were built before 1970, and a sufficiently large data set was therefore available to carry out the analyses at an urban scale.

The type of retrofitting interventions identified from the retrofit database were the installation of thermostatic valves, thermal insulation of the roof, thermal insulation of the slab/floor, the replacement of windows, thermal insulation of vertical walls and window replacements. Figure 5 shows the different distributions of the typology of retrofitting for the 33 meshes of the city of Turin served by the DH network. It is possible to observe that the main interventions were the thermal insulation of walls and window replacements. No energy retrofitting measures had been carried out in some meshes. There were only 49 EPCs for the detached houses (see Fig. 5) with information about retrofitting interventions.

In order to improve the results of the engineering models, some new building data inputs were calculated at a district scale. The $U$-values of opaque

Table 1 Number of EPCs in Turin and in the 33 considered meshes distinguishing between the motivations for their release

\begin{tabular}{llllllll}
\hline Number of EPCs & Area & Generic & & Retrofit & & RES \\
& & Flats & Detached Houses & Flats & Detached Houses & Flats & Detached Houses \\
& \multirow{2}{*}{ Turin } & 167,899 & 5632 & 5786 & 760 & 4030 & 374 \\
& & $(95 \%)$ & $(83 \%)$ & $(3 \%)$ & $(11 \%)$ & $(2 \%)$ & $(6 \%)$ \\
& \multirow{3}{*}{33 districts } & 53,174 & 429 & 992 & 49 & 581 & 51 \\
& & $(97 \%)$ & $(81 \%)$ & $(2 \%)$ & $(9 \%)$ & $(1 \%)$ & $(10 \%)$ \\
\hline
\end{tabular}




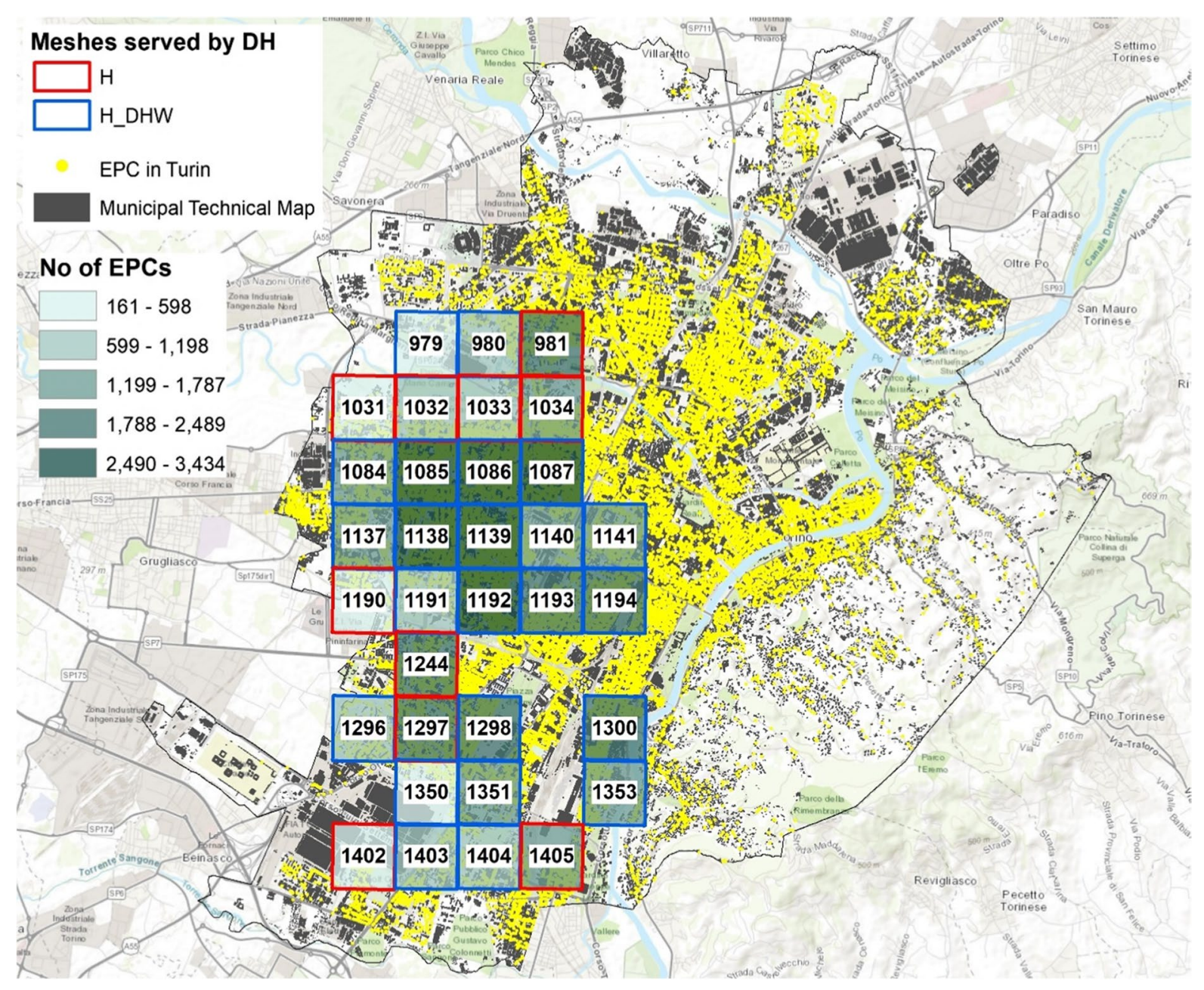

Fig. 3 A case study of Turin with information about the buildings, the 33 meshes connected to the DH network $(1 \mathrm{~km} \times 1 \mathrm{~km}$ dimensions), the ID mesh, and the distribution of the EPCs

envelopes $\left(U_{o p}\right)$ and glazing $\left(U_{g}\right)$, and the $\eta$-values were calculated from the EPC database for the city of Turin, considering the construction period and the motivation for their release (generic and retrofit). It emerges, from Fig. 6, that the efficiency level of residential buildings built in the 1971-1980 period, and
Fig. 4 Distributions of the thermal transmittance $U_{o p}$ a and system efficiency $\eta H \mathbf{b}$ values for flats built before 1919, as taken from the generic database

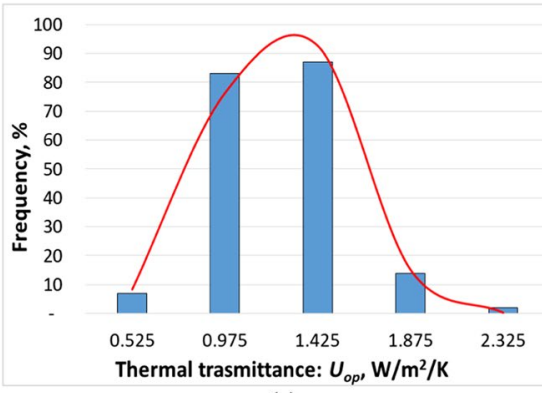

(a)

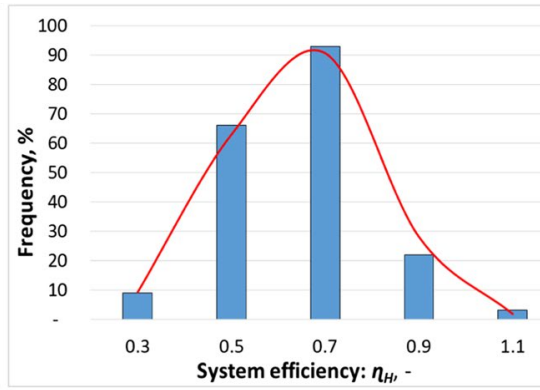

(b) 


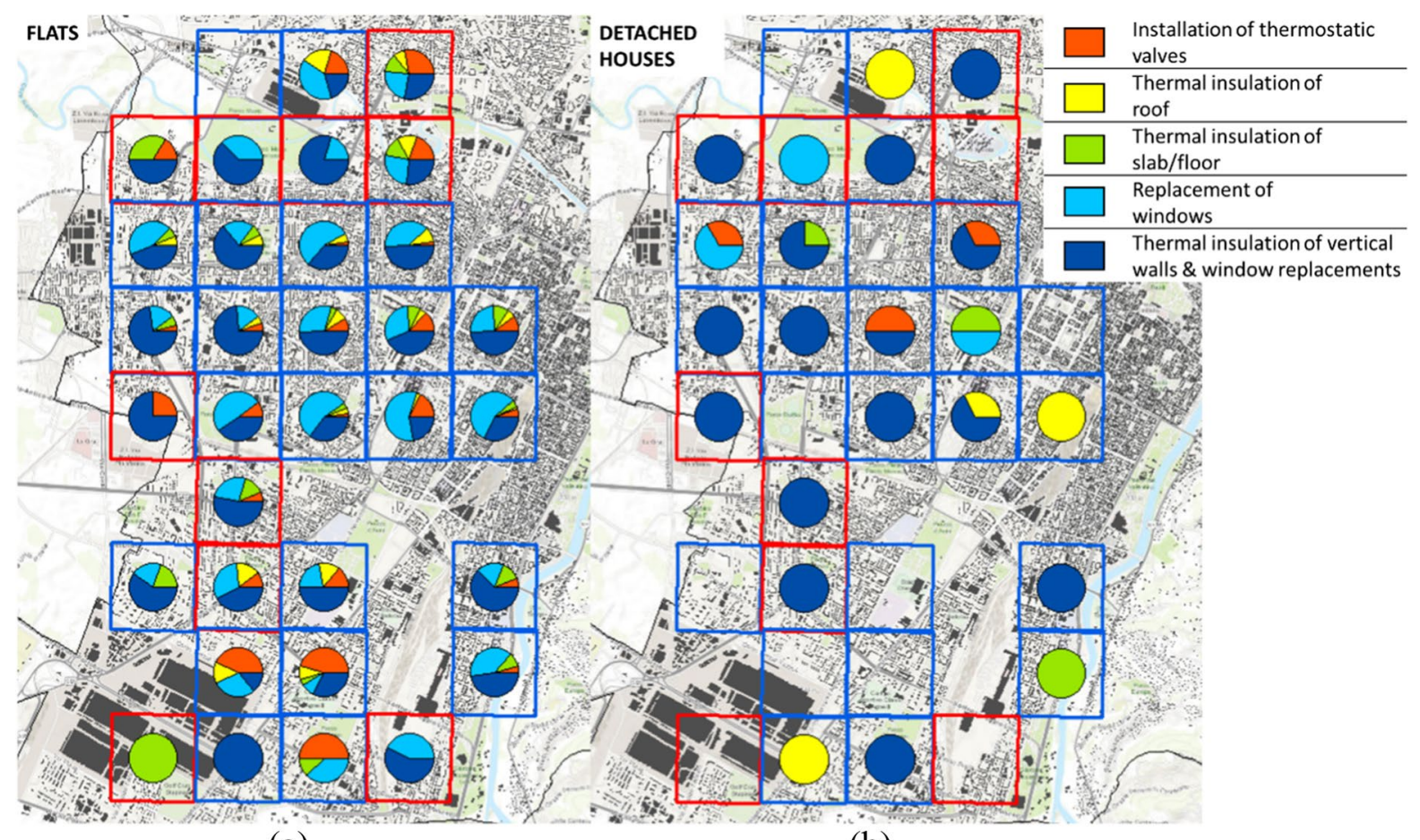

(a)

(b)

Fig. 5 Typologies of retrofitting interventions in the 33 meshes connected to the DH network: a flats and b detached houses (EPC database up to September 2015)

in particular for the last three construction period classes, has improved, and shows low $U$-values and high $\eta$-values. This trend is more evident after energy retrofitting interventions. The obtained results were less accurate when there were fewer certificates. For example, the $U_{o p \text {,generic }}$ value was lower than $U_{\text {op,retrofit }}$ for the 1991-1905 period, and the $U_{g, g e n e r i c}$ value was at almost the same level as $U_{g, \text { retrofit }}$. This is due to the fact that only 88 certificates were available for buildings built in the 1991-1995 period, and this number represents $2 \%$ of the retrofitting database; in addition, as they are new buildings, they are unlikely to have been retrofitted.

Specific values of $U_{o p}, U_{g}, \eta_{H}$ and $\eta_{D H W}$ were then calculated, according to the EPCs in the DH area, from the EPC database for each mesh (column 1
Fig. 6 Thermal transmittances and system efficiency values elaborated from the EPC database distinguishing between generic and retrofit motivations (EPC database up to September 2015)

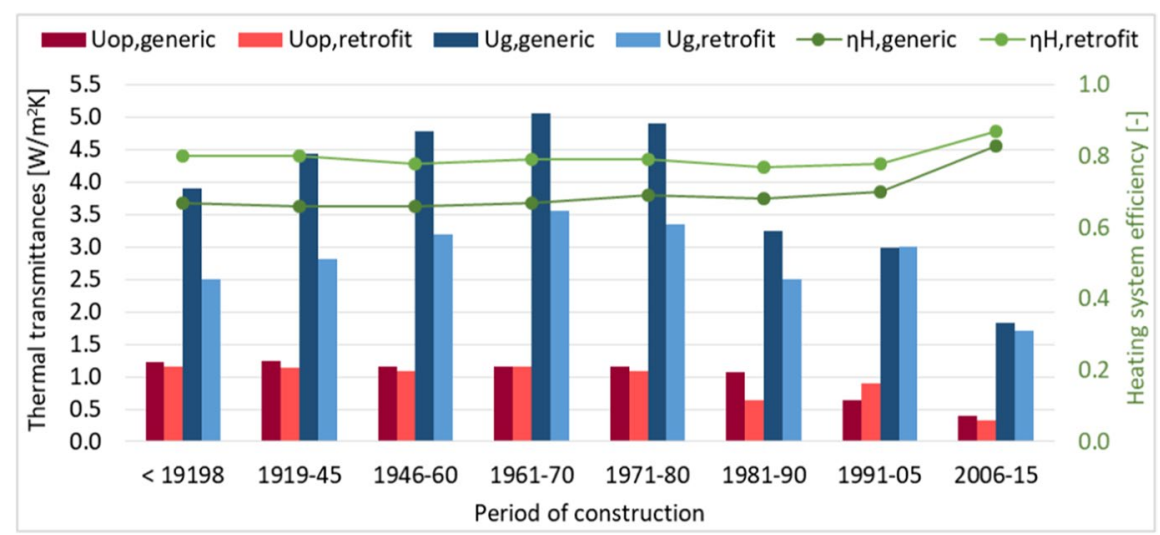


indicates the ID mesh code, see Table 2) for the different construction periods and considering the quota of heated volumes served by the DHN.

Table 2 shows a comparison between the old (i) and the new (ii) values of $U_{o p}, U_{g}, \eta_{H}$ and $\eta_{D H W}$ for each mesh. The number of EPCs in each mesh, the percentage of heated volumes of EPCs served by the DH network, the prevalent period of construction and the prevalent energy class (from $A+$ to $G$ ) with the percentage, distinguishing between the generic database with 41,190 EPCs and the retrofit database with only 658 EPCs, are also indicated in Table 2. It is possible to observe that the energy class of generic buildings is worse in almost all the meshes, and is equal to G. On the one hand, this is negative from an energy point of view, but at the same time it can represent a possibility of promoting EE measures, as only $2 \%$ of the buildings had been retrofitted by 2015 , with a no significant improvement in the energy class.

\section{Results}

This work has analysed the EPCs database of residential buildings in the Piedmont Region (Italy). The EPCs have been elaborated through the use of a GIS tool to assess the distribution of building characteristics and EE measures in the city of Turin. The residential energy consumptions $(\mathrm{H}+\mathrm{DHW}$ and $\mathrm{H})$ have been simulated through the use of a monthly engineering model of buildings served by the DHN. The model was only applied to the district heading area of the city, since the accuracy of the modal had already been validated using district heating consumption. The energy simulations of these models have been improved using EPC information as input data, and the validation has been made by comparing the measured and simulated data of three consecutive heating seasons (2012/2013, 2013/2014 and 2014/2015). An urban energy atlas has been implemented for the city and EE scenarios have been elaborated according to the EPC database.

\section{Retrofitting interventions and energy saving analysis}

The adopted EE measures consider different interventions, such as thermal insulation of the building envelopes and/or the replacement of generation systems, and take into account all the constraints of the built environment and the real urban context.
Table 3 describes the data pertaining to the homogeneous groups of flats from different construction periods, as well as the median values of the energy performance index of the generic EPCs and retrofit EPCs. The difference between these two indicators allows the energy savings to be calculated considering the period of construction. It is possible to observe that the highest energy savings can be obtained for the older buildings, built before 1980. This trend emerges because residential buildings built before 1976 (the year in which the first National Law on EE was enacted) have a worse EP and a higher potential for energy savings than newer buildings. The accuracy of the energy savings also depends on the number of EPCs from which it was calculated (a higher number of EPCs makes the result more accurate).

A similar assessment has been made for the installation of the main renewable solar energy technologies (Table 4): biomass boiler, PV (photovoltaic panels), ST (solar thermal collectors) and HP (heat pump). Because of the small number of EPCs, it was not possible to distinguish between the buildings on the basis of the period of construction and the prevalent period of construction was therefore considered for the energy saving analysis. It can be observed, in Table 4, that the greatest energy savings are obtained for two combined renewable technologies, that is, PV panels and ST collectors.

The same analysis was conducted for detached houses. In this case, the results were not particularly accurate, due to the low number of EPCs available (Tables 5 and 6).

Figure 7 shows the cumulative energy savings achieved for flats and for detached houses after retrofitting measures, while Fig. 8 describes the results pertaining to cumulative energy savings after the installation of RES technologies. Although the number of detached houses in the 33 considered districts of Turin is much lower than the number of flats in condominiums, the cumulative energy savings and the retrofitted area of the detached residential buildings still make a significant contribution on the retrofit trends in city.

Tables 7 and 8 show the main results of the energy savings, according to the construction period, and the number of EPCs for each type of renovation: thermal insulation of the roof, thermal insulation of the slab/ floor, thermal insulation of vertical walls and/or window replacements, and installation of thermostatic 


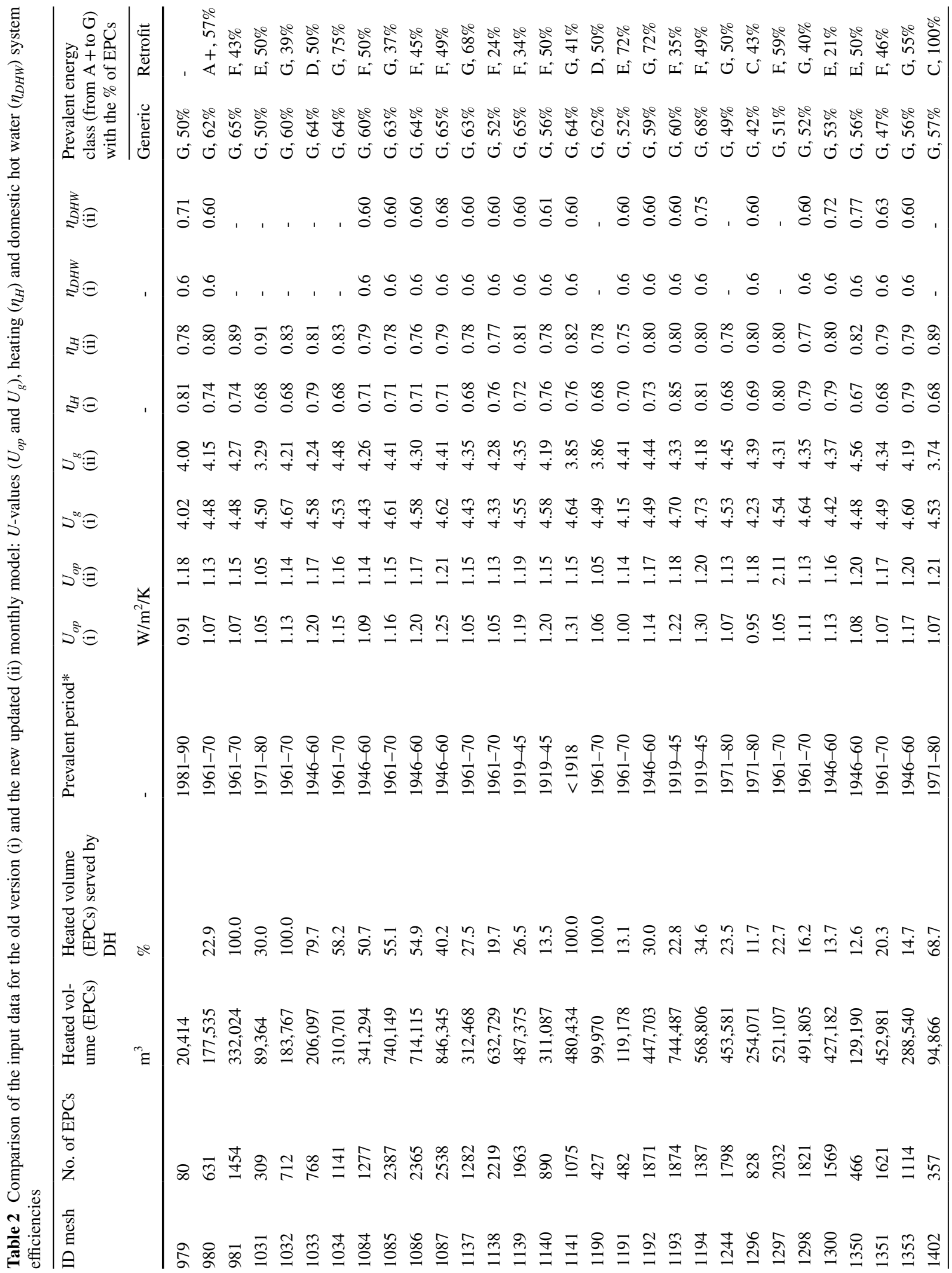


valves. The percentage of certificates is indicated for each intervention according to the construction period, and the percentage of energy savings, calculated according to Eq. 2, is reported in the last column. The most effective interventions are the thermal insulation of vertical walls and window replacements for both flats and detached houses. Since the accuracy of the results depends on the number of EPCs, more reliable results were obtained for flats built before 1970. Certificates were not available for some construction periods, and in such cases the percentage was $0 \%$.

\section{Engineering model application}

The presented engineering model is able to predict the energy consumptions, with monthly time steps, for $\mathrm{H}$ and DHW. The accuracy of these models depends not only on the input data but also on (i) the distribution of the type of users, since the model simulates residential consumption at a district scale, and the percentage and number of residential buildings in each district; (ii) the percentage of heated volume served by the $\mathrm{DH}$ network, and the models were in fact validated using the DH consumptions at a district scale; (iii) and the dimension of the used territorial unit (Mutani \& Todeschi, 2019, 2020). A total of 26 meshes were selected from the original 33 to show the obtained results; some meshes were excluded due to the presence of erroneous data in the input database. Figure 9 shows a comparison of the measured ( $\boldsymbol{x}$-axis) and the simulated data ( $\boldsymbol{y}$-axis) for the old (i) and the new updated (ii) engineering models. The global consumptions (of three consecutive heating seasons) are indicated for each mesh, distinguishing between the $\mathrm{H}+\mathrm{DHW}$ model (Fig. 9a) and the $\mathrm{H}$ model (Fig. 9b). It is possible to observe a general improvement in the accuracy for both models, especially for the $\mathrm{H}+\mathrm{DHW}$ model.

The relative error, $E_{r}$, (calculated as the difference between the measured and simulated data, divided by the measured data) was used to assess the precision of the model. Figures 10 and 11 show the global relative error $\left(E_{\mathrm{r} \text {,global }} \%\right)$ of the $\mathrm{H}+\mathrm{DHW}$ and $\mathrm{H}$ models for each mesh. The errors for the updated models (ii) were generally lower, although this was not observed in some meshes where there 
Table 3 Characteristics of the flats according to their period of construction in 33 districts of Turin

\begin{tabular}{llllllc}
\hline $\begin{array}{l}\text { Period of con- } \\
\text { struction }\end{array}$ & $\begin{array}{l}\text { Number of EPCs } \\
\text { retrofitted }\end{array}$ & Retrofit $\left(\mathrm{m}^{2}\right)$ & $\begin{array}{l}E P_{\text {gl,retrofit }}(\mathrm{kWh} / \\
\left.\mathrm{m}^{2} / \mathrm{y}\right) \text { median }\end{array}$ & $\begin{array}{l}E P_{\text {gl,generic }}(\mathrm{kWh} / \\
\left.\mathrm{m}^{2} / \mathrm{y}\right) \text { median }\end{array}$ & $\begin{array}{l}E_{\text {savings,retrofit }} \\
\left(\mathrm{kWh} / \mathrm{m}^{2} / \mathrm{y}\right)\end{array}$ & $\begin{array}{l}E_{\text {savings,retrofit }} \\
(\%)\end{array}$ \\
\hline$<1918$ & 186 & 15,554 & 142 & 210 & 68 & 32 \\
$1919-45$ & 230 & 18,389 & 159 & 235 & 76 & 33 \\
$1946-60$ & 336 & 26,060 & 172 & 227 & 55 & 24 \\
$1961-70$ & 172 & 14,644 & 159 & 218 & 58 & 27 \\
$1971-80$ & 22 & 2111 & 137 & 209 & 18 & 34 \\
$1981-90^{*}$ & 18 & 1947 & 157 & 175 & 14 & 10 \\
$1991-05^{*}$ & 17 & 1790 & 123 & 137 & 114 & 4 \\
$>2006 *$ & 11 & 680 & 110 & & 4 & 4 \\
\hline
\end{tabular}

*The number of EPCs was not sufficient to identify accurate trends for this construction period

Table 4 Energy performance of the flats according to their renewable energy technology in 33 districts of Turin

\begin{tabular}{|c|c|c|c|c|c|c|}
\hline RES technology (main period) & $\begin{array}{l}\text { No. of EPCs } \\
\text { retrofitted }\end{array}$ & Retrofit $\left(\mathrm{m}^{2}\right)$ & $\begin{array}{l}E P_{g l, R e s}(\mathrm{kWh} / \\
\left.\mathrm{m}^{2} / \mathrm{y}\right) \text { median }\end{array}$ & $\begin{array}{l}E P_{\text {gl,generic }}(\mathrm{kWh} / \\
\left.\mathrm{m}^{2} / \mathrm{y}\right) \text { median }\end{array}$ & $\begin{array}{l}E_{\text {savings, Res }} \\
\left(\mathrm{kWh} / \mathrm{m}^{2} / \mathrm{y}\right)\end{array}$ & $E_{\text {savings,Res }}(\%)$ \\
\hline Biomass boiler (1946-60) & 24 & 1714 & 191 & 226 & 35 & 16 \\
\hline Heat Pump (1919-45 and > 2006) & 23 & 1834 & 116 & 162 & 46 & 28 \\
\hline PV $(>2006)$ & 31 & 2194 & 95 & 114 & 19 & 30 \\
\hline PV-ST (> 2006) & 66 & 4531 & 53 & 114 & 61 & 51 \\
\hline ST $(>2006)$ & 437 & 30,977 & 80 & 114 & 34 & 38 \\
\hline
\end{tabular}

were only a few EPCs and only a few flats were served by the DHN (see Table 2). In this case, the number of EPCs and/or the quota served by the DHN were not sufficient to describe the real characteristics of the residential building stock. Regarding the H+DHW model (Fig. 10), no improvement was observed in the energy simulation in meshes 1298 and 1404, which showed an average $E_{\mathrm{r} \text {,global }}$ of $16 \%$. In this case, the increase in error depends on the quota served by the DHN; in fact, only $16 \%$ of the EPCs located in the district are served by the DHN in mesh 1298 and this percentage is about 19\% in mesh 1404 (see Table 2). As far as the $\mathrm{H}$ model is concerned, an $E_{\text {r,global }}$ of 13 and 8\%, respectively, can be observed in meshes 1033 and 1297 (Fig. 11). There are just over 700 EPCs in mesh 1033 (see Table 2), and only 23\% of the EPCs in mesh 1297 are served by the DHN. The number of EPCs in

Table 5 Characteristics of the detached houses according to their period of construction in 33 districts of Turin

\begin{tabular}{|c|c|c|c|c|c|c|}
\hline $\begin{array}{l}\text { Period of con- } \\
\text { struction }\end{array}$ & $\begin{array}{l}\text { Number of EPCs } \\
\text { retrofitted }\end{array}$ & Retrofit $\left(\mathrm{m}^{2}\right)$ & $\begin{array}{l}E P_{\text {gl,retrofit }}(\mathrm{kWh} / \\
\left.\mathrm{m}^{2} / \mathrm{y}\right) \text { median }\end{array}$ & $\begin{array}{l}E P_{\text {gl,generic }}(\mathrm{kWh} / \\
\left.\mathrm{m}^{2} / \mathrm{y}\right) \text { median }\end{array}$ & $\begin{array}{l}E_{\text {savings,retrofit }} \\
\left(\mathrm{kWh} / \mathrm{m}^{2} / \mathrm{y}\right)\end{array}$ & $\begin{array}{l}E_{\text {savings, retrofit }} \\
(\%)\end{array}$ \\
\hline$<1918^{*}$ & 6 & 3586 & 182 & 264 & 82 & 31 \\
\hline $1919-45^{*}$ & 4 & 1303 & 200 & 287 & 87 & 30 \\
\hline $1946-60$ & 23 & 5942 & 240 & 267 & 27 & 10 \\
\hline $1961-70^{*}$ & 10 & 4299 & 224 & 280 & 56 & 20 \\
\hline $1971-80^{*}$ & 1 & 160 & 152 & 234 & 82 & 35 \\
\hline $1981-90^{*}$ & 3 & 359 & 139 & 191 & 52 & 27 \\
\hline $1991-05^{*}$ & 1 & 53 & 98 & 185 & 87 & 47 \\
\hline$>2006^{*}$ & 1 & 57 & 104 & 112 & 8 & 7 \\
\hline
\end{tabular}

*The number of EPCs was not sufficient to identify accurate trends for this construction period 
Table 6 Energy performance of the detached houses according to their renewable energy technology in 33 districts of Turin

\begin{tabular}{|c|c|c|c|c|c|c|}
\hline RES technology (main period) & $\begin{array}{l}\text { Number of } \\
\text { EPCs retrofit- } \\
\text { ted }\end{array}$ & Retrofit $\left(\mathrm{m}^{2}\right)$ & $\begin{array}{l}E P_{\text {gl,retrofit }}(\mathrm{kWh} / \\
\left.\mathrm{m}^{2} / \mathrm{y}\right) \text { median }\end{array}$ & $\begin{array}{l}E P_{\text {gl,generic }}(\mathrm{kWh} / \\
\left.\mathrm{m}^{2} / \mathrm{y}\right) \text { median }\end{array}$ & $\begin{array}{l}E_{\text {savings, Res }} \\
\left(\mathrm{kWh} / \mathrm{m}^{2} / \mathrm{y}\right)\end{array}$ & $E_{\text {savings,Res }}(\%)$ \\
\hline Biomass boiler (1961-70)* & 1 & 81 & 266 & 280 & 14 & 5 \\
\hline PV $(1946-60)^{*}$ & 5 & 1229 & 152 & 267 & 154 & 58 \\
\hline PV-ST (1946-60)* & 1 & 99 & 84 & 267 & 183 & 69 \\
\hline ST $(>2006)$ & 44 & 7072 & 90 & 111 & 45 & 40 \\
\hline
\end{tabular}

*The number of EPCs is not sufficient to identify accurate trends for this construction period

each mesh and the quota of EPCs served by the DHN are important to describe the characteristics of the buildings; when the EPC quota was not sufficient, the input data optimisation was invalidated. However, the input data improvement in all the other meshes has given an important contribution to the assessment of the EP of buildings at an urban scale.

\section{Energy efficiency scenarios}

In line with the most common efficiency measures used in the city and taking into account the real characteristics of the considered buildings, two EE scenarios have been hypothesised in the district heating area of Turin: (i) thermal insulation of the opaque envelope; (ii) thermal insulation of the opaque envelope and window replacements. Effective energy retrofitting measures can be identified using these models and considering the most critical areas with the worst air quality conditions and highest building energy consumptions.

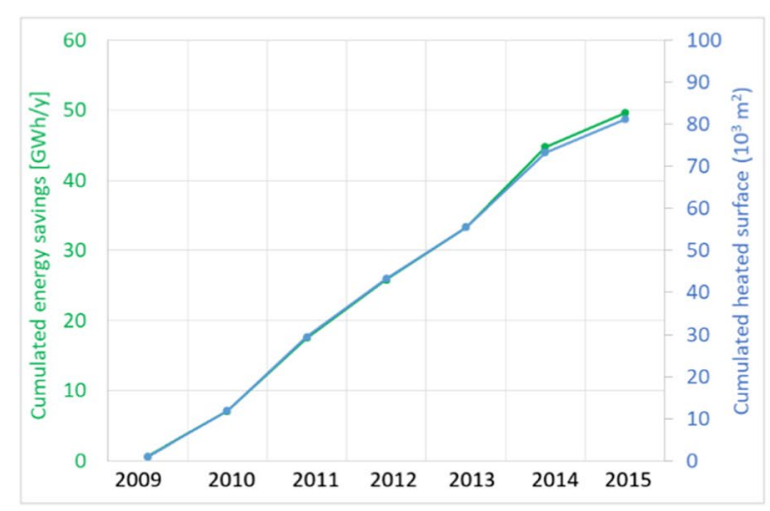

(a)
Figure 12 shows the monthly space heating consumption of meshes 1086 and 1193 for the 2014-2015 heating season. The measured data (in grey) were compared with the simulated ones (in red), distinguishing between the old model (i) and the optimised model (ii). The seasonal relative error decreases from 8.6 to $7.4 \%$ for mesh 1086 as a result of the optimisation, and from 3.4 to $0.1 \%$ for mesh 1193. Two retrofitting scenarios were investigated (in blue) considering the most common EE measures: the thermal insulation of the opaque envelope of residential buildings was hypothesised in the first one (S1), while window replacement was added to S1 in the second scenario (S2). The greatest energy savings occur during the winter months, when the energy consumption for heating is higher. An annual energy saving of $4400 \mathrm{MWh} /$ year is observed in mesh 1086, and the energy saving is $5072 \mathrm{MWh} /$ year in mesh 1193.

The monthly $\mathrm{H}$ and DHW models were then used to quantify the energy savings of residential buildings

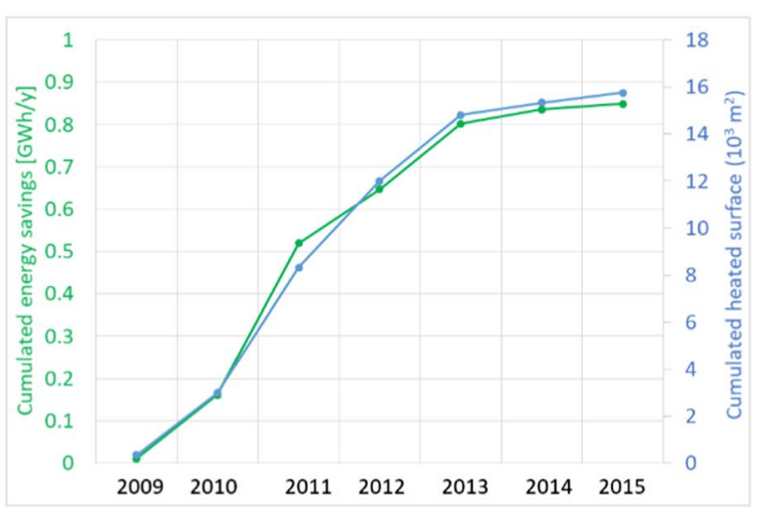

(b)

Fig. 7 Cumulative energy savings for $\mathbf{a}$ the flats and $\mathbf{b}$ detached houses in the 33 considered districts in Turin 


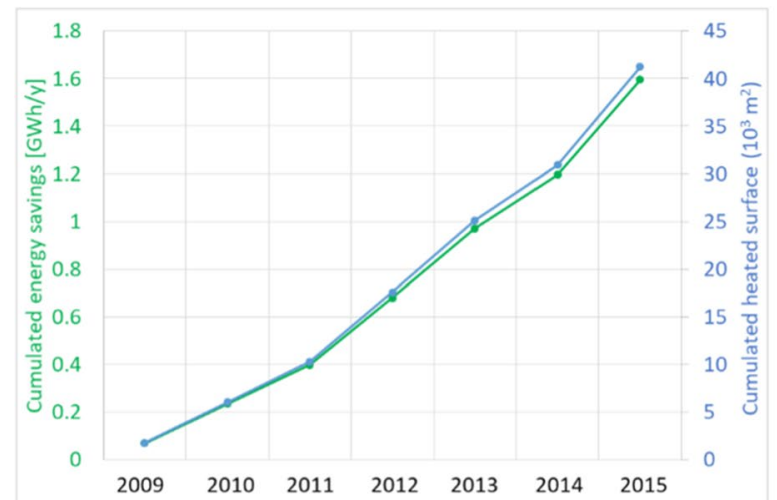

(a)

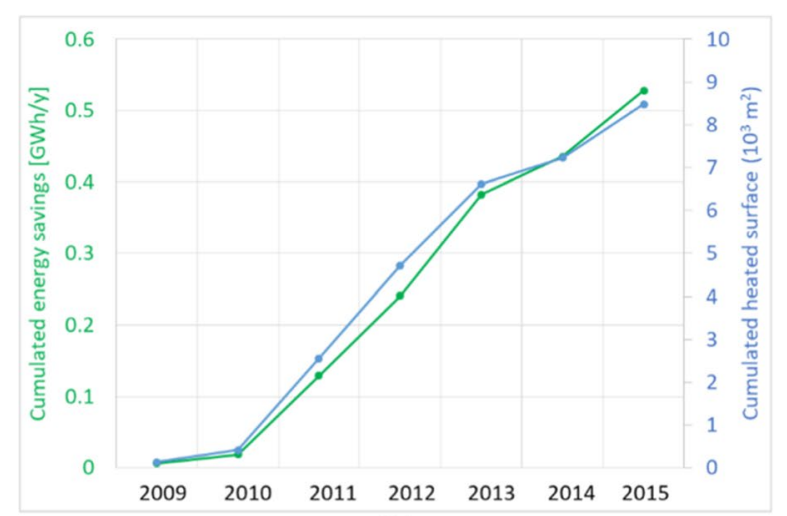

(b)

Fig. 8 Cumulative energy savings for renewable energy technologies for $\mathbf{a}$ the flats and $\mathbf{b}$ detached houses in the 33 considered districts in Turin

served by the DHN, and the GHG emission reduction was assessed using 0.154 tonCO $\mathrm{C}_{2} / \mathrm{MWh}$ for district heating (Mutani \& Todeschi, 2018) (that is, the conversion emission factors of the DHN). In the first scenario, the thermal transmittance values of the opaque envelope after retrofitting interventions were used as input data, considering the quota of residential buildings already renovated and the main construction period. In this case, an energy saving of 22,251 $\mathrm{MWh} / \mathrm{y}$ is obtained and a consequent reduction in GHG emissions of 3404 tonCO $\mathrm{CO}_{2 \mathrm{eq}} / \mathrm{y}$. On the other hand, it is possible to achieve an annual energy saving of 79,064 MWh/y with a GHG reduction of 12,097
tonCO $\mathrm{C}_{2 \mathrm{eq}} / \mathrm{y}$ for the thermal insulation of the opaque envelope and window replacements.

With this place-based tool, it is possible to visualise the distribution of energy savings and GHG emission reductions at a territorial level. Figure 13 shows an example of the results of the two scenarios at a district scale $(1 \mathrm{~km} \times 1 \mathrm{~km}$ mesh $)$. The annual energy saving (MWh $10^{3} / \mathrm{y}$ ) is indicated for each mesh. From the results of this work, it has emerged that it would be possible to reduce the energy consumption of residential buildings with low energy performance served by the DHN by thermally insulating the opaque envelope and replacing the windows. Other measures

Table 7 Energy consumption of the flats according to their period of construction after the main retrofitting interventions in the 33 considered districts in Turin

\begin{tabular}{|c|c|c|c|c|c|c|c|c|c|}
\hline Period & $\begin{array}{l}\text { No. of } \\
\text { EPCs }\end{array}$ & $\begin{array}{l}E P_{g l, i n t} \\
\left(\mathrm{kWh} / \mathrm{m}^{2} / \mathrm{y}\right)\end{array}$ & $\begin{array}{l}\text { EPCs \%, } \\
\text { int. roof } \\
\text { insulation }\end{array}$ & $\begin{array}{l}\text { EPCs \%, int. } \\
\text { slab/floor } \\
\text { insulation }\end{array}$ & $\begin{array}{l}\text { EPCs \%, } \\
\text { int. wall } \\
\text { insulation } \\
\text { and window } \\
\text { replace- } \\
\text { ments }\end{array}$ & $\begin{array}{l}\text { EPCs \%, } \\
\text { int. thermo- } \\
\text { static valves }\end{array}$ & $\begin{array}{l}\text { EPCs \%, } \\
\text { int. window } \\
\text { replace- } \\
\text { ments }\end{array}$ & $\begin{array}{l}E P_{\text {gl,reach,int }} \\
\left(\mathrm{kWh} / \mathrm{m}^{2} / \mathrm{y}\right)\end{array}$ & $\begin{array}{l}\text { Medium } \\
\text { term } \\
E_{\text {savings }}\end{array}$ \\
\hline$<1918$ & 186 & 142 & $3 \%$ & $4 \%$ & $27 \%$ & $6 \%$ & $33 \%$ & 109 & $23 \%$ \\
\hline $1919-45$ & 230 & 159 & $8 \%$ & $2 \%$ & $27 \%$ & $7 \%$ & $27 \%$ & 116 & $27 \%$ \\
\hline $1946-60$ & 336 & 172 & $2 \%$ & $5 \%$ & $37 \%$ & $6 \%$ & $28 \%$ & 133 & $22 \%$ \\
\hline $1961-70$ & 172 & 159 & $3 \%$ & $5 \%$ & $32 \%$ & $16 \%$ & $17 \%$ & 118 & $26 \%$ \\
\hline $1971-80$ & 22 & 137 & $0 \%$ & $0 \%$ & $41 \%$ & $5 \%$ & $18 \%$ & 96 & $30 \%$ \\
\hline $1981-90^{*}$ & 18 & 157 & $0 \%$ & $0 \%$ & $11 \%$ & $6 \%$ & $11 \%$ & 143 & $9 \%$ \\
\hline $1991-05^{*}$ & 17 & 123 & $0 \%$ & $6 \%$ & $24 \%$ & $12 \%$ & $24 \%$ & 106 & $13 \%$ \\
\hline$>2006^{*}$ & 11 & 110 & $0 \%$ & $0 \%$ & $9 \%$ & $0 \%$ & $9 \%$ & 89 & $18 \%$ \\
\hline
\end{tabular}

*The number of EPCs was not sufficient to identify accurate trends for this construction period 
Table 8 Energy consumption of the detached houses according to their period of construction after the main retrofitting interventions in the 33 considered districts in Turin

\begin{tabular}{|c|c|c|c|c|c|c|c|c|c|}
\hline Period & $\begin{array}{l}\text { No. of } \\
\text { EPCs }\end{array}$ & $\begin{array}{l}E P_{g l, \text { int }} \\
\left(\mathrm{kWh} / \mathrm{m}^{2} / \mathrm{y}\right)\end{array}$ & $\begin{array}{l}\text { EPCs \%, } \\
\text { int. roof } \\
\text { insulation }\end{array}$ & $\begin{array}{l}\text { EPCs \%, } \\
\text { int. slab/ } \\
\text { floor insula- } \\
\text { tion }\end{array}$ & $\begin{array}{l}\text { EPCs \%, } \\
\text { int. wall } \\
\text { insula- } \\
\text { tion and } \\
\text { windows } \\
\text { replace- } \\
\text { ments }\end{array}$ & $\begin{array}{l}\text { EPCs \%, } \\
\text { int. thermo- } \\
\text { static valves }\end{array}$ & $\begin{array}{l}\text { EPCs \%, } \\
\text { int. window } \\
\text { replace- } \\
\text { ments }\end{array}$ & $\begin{array}{l}E P_{\text {gl,reach,int }} \\
\left(\mathrm{kWh} / \mathrm{m}^{2} / \mathrm{y}\right)\end{array}$ & $\begin{array}{l}\text { Medium } \\
\text { term } \\
E_{\text {savings }}\end{array}$ \\
\hline$<1918^{*}$ & 6 & 182 & $17 \%$ & $0 \%$ & $50 \%$ & $0 \%$ & $17 \%$ & 128 & $30 \%$ \\
\hline $1919-45^{*}$ & 4 & 200 & $25 \%$ & $25 \%$ & $25 \%$ & $25 \%$ & $0 \%$ & 133 & $33 \%$ \\
\hline $1946-60$ & 23 & 240 & $9 \%$ & $4 \%$ & $52 \%$ & $9 \%$ & $9 \%$ & 170 & $29 \%$ \\
\hline $1961-70^{*}$ & 10 & 224 & $0 \%$ & $10 \%$ & $80 \%$ & $0 \%$ & $10 \%$ & 176 & $22 \%$ \\
\hline $1971-80^{*}$ & 1 & 152 & $0 \%$ & $0 \%$ & $100 \%$ & $0 \%$ & $0 \%$ & 120 & $21 \%$ \\
\hline $1981-90^{*}$ & 3 & 139 & $0 \%$ & $0 \%$ & $33 \%$ & $0 \%$ & $0 \%$ & 132 & $5 \%$ \\
\hline $1991-05^{*}$ & 1 & 98 & $0 \%$ & $0 \%$ & $100 \%$ & $0 \%$ & $0 \%$ & 63 & $36 \%$ \\
\hline$>2006^{*}$ & 1 & 125 & $0 \%$ & $0 \%$ & $0 \%$ & $0 \%$ & $0 \%$ & 104 & $17 \%$ \\
\hline
\end{tabular}

*The number of EPCs was not sufficient to identify accurate trends for this construction period

could be used to further reduce the energy consumption of these buildings, for example, the installation of thermostatic valves and the use of RES technologies. The impact of these measures will be investigated in future work using an updated EPC database.

\section{Discussion}

In this work, a new retrofitting database has been created using EPCs data. It was necessary to perform a statistical analysis of the EPC data when working at an urban scale in order to discard anomalous data and to find characteristic data of the buildings.
Summarising: (i) the input data of an engineering model were improved using the EPC data; (ii) the energy savings that could be attained as a result of retrofitting interventions were investigated with the same database considering the characteristics of the buildings; (ii) thanks to these assessments, the EE interventions that can be done in the city have been identified and the energy saving have been quantified.

It is necessary to consider the costs of the interventions for the application of EE scenarios. An analysis on the costs of EE measures, in which National trends are taken into account, is described in this section. Four retrofitting interventions have been considered to improve the EP of building: thermal insulation of
Fig. 9 Comparison of the measured and simulated energy consumptions for three consecutive heating seasons (2012-13, 2013-14 and 2014-15) for the old (i) and new (ii) USEMs: a the $\mathrm{H}+\mathrm{DHW}$ model and $\mathrm{b}$ the $\mathrm{H}$ model



(a)

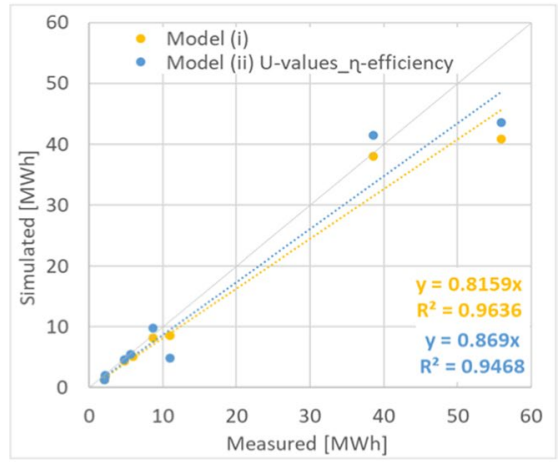

(b) 


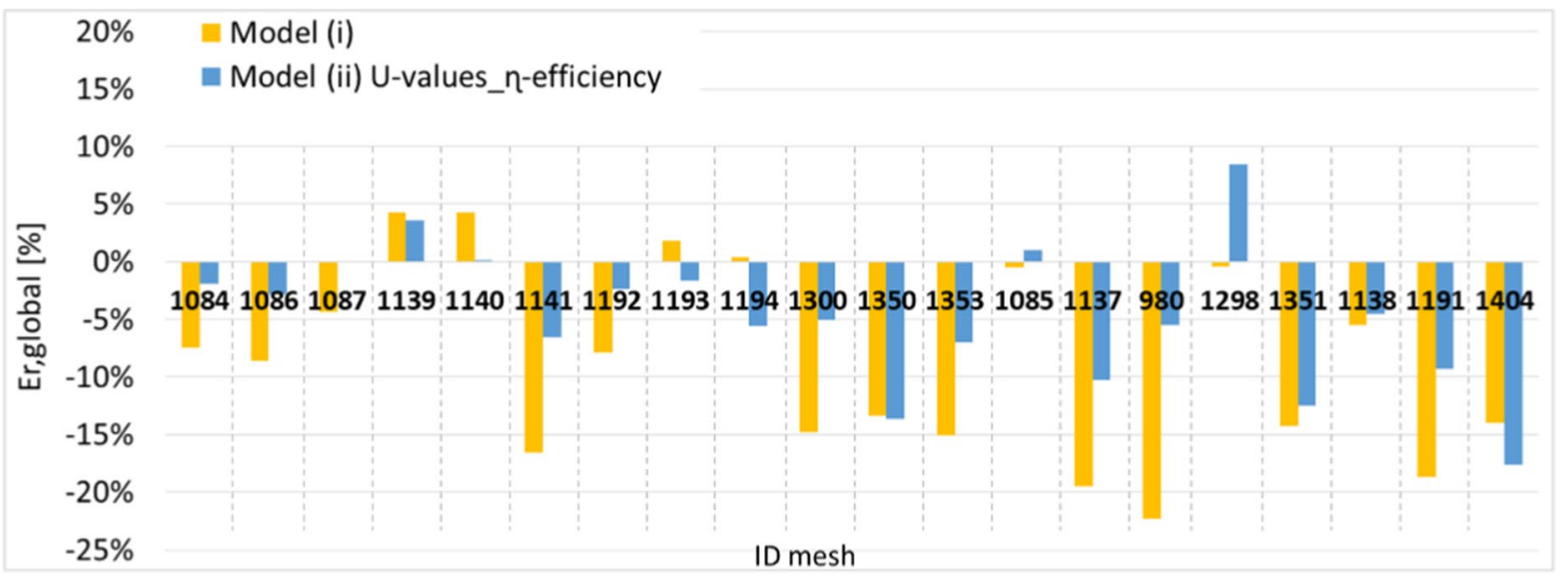

Fig. 10 Comparison of the global relative error $\left(E_{r, g l o b a l} \%\right)$ for the old (i) and new (ii) monthly H+DHW models

the roof, thermal insulation of the slab/floor, window replacements, and thermal insulation of vertical walls and window replacements. Table 9 shows the cost of such interventions, as elaborated from the ENEA (Italian National Agency for New Technologies, Energy and Sustainable Economic Development) Report on EE, to monitor and evaluate developments of national energy policies (updated to 2019) and energy savings (\%) based on the EPC database.

The costs of the interventions indicated in Table 9 were applied to the city of Turin, and Fig. 14 shows the costs of the EE scenarios for each mesh (expressed in $\mathrm{M} €$ ) applied to the whole district heating area considering the two analysed scenarios. Higher costs in general correspond to areas with more significant energy savings (see Fig. 13). Multi-criteria analyses will be carried out in future works to identify effective financial schemes to promote $\mathrm{EE}$ in buildings and to assess the cost-effectiveness of EE measures, considering the existing tax incentives (Baldini et al., 2020).

This work shows how an improvement of input data can reduce the output errors of an energy model by approximately $4 \%$. This has been possible thanks to the processing and elaboration of the EPC data and the creation of a GIS retrofitting database. The
Fig. 11 Comparison of the global relative error ( $E_{\mathrm{r}, \text { global }}$ \%) for the old (i) and new (ii) monthly $\mathrm{H}$ models

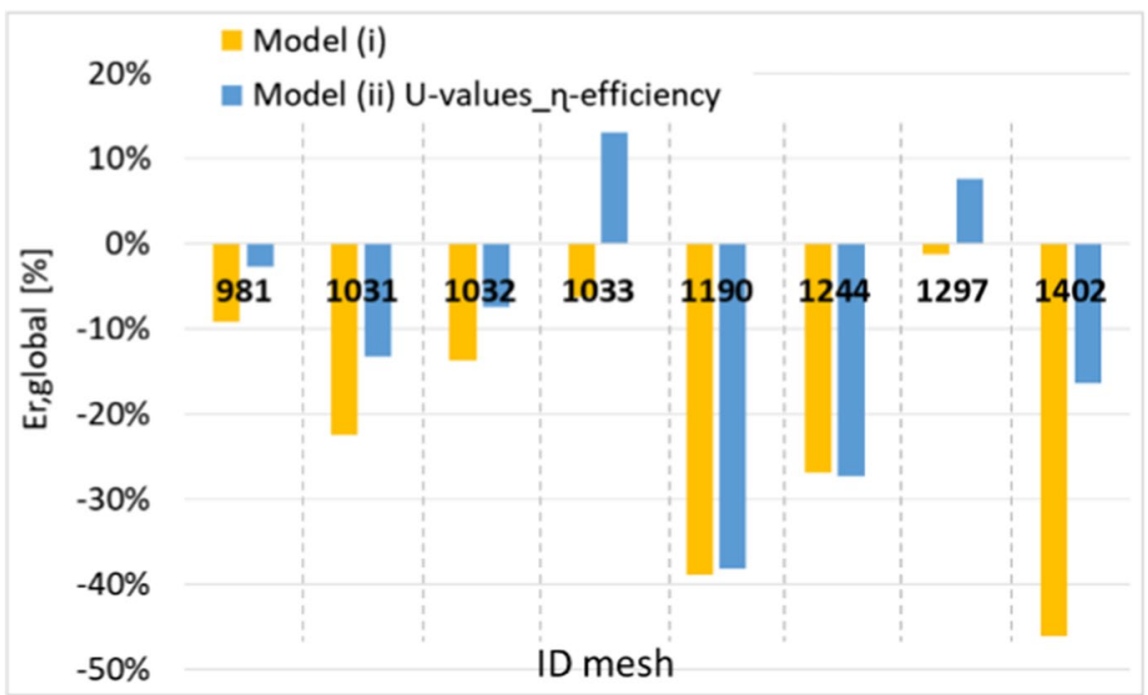




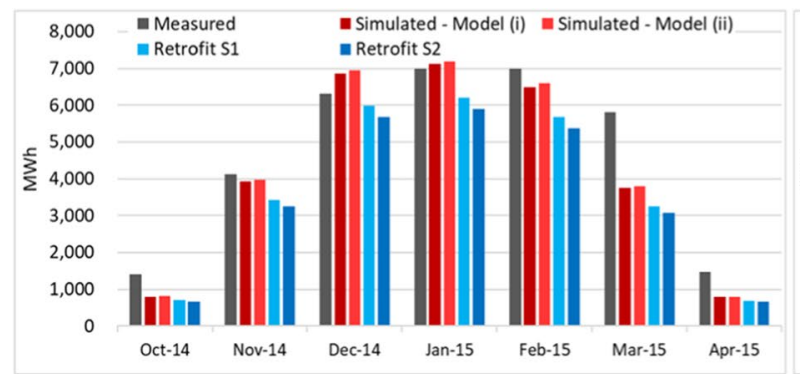

(a)

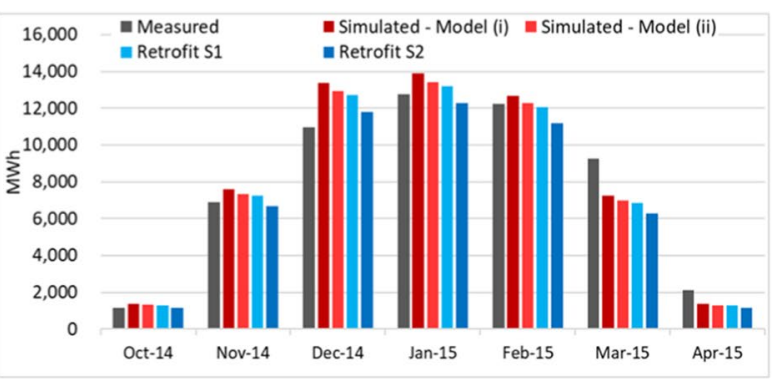

(b)
Fig. 12 Monthly results of DH consumption: measured, simulated (models $\mathrm{i}$ and ii), with retrofitting measures (scenario 1 with thermal insulation of the opaque envelope and scenario
2 with thermal insulation of the opaque envelope and window replacements) for a mesh 1086 and $\mathbf{b}$ mesh 1193

the methodology. Socio-economic factors, such as income level, type of income, number of occupants and their age, are in fact known to influence the energy consumption in buildings and the applicability and efficacy of energy policies (van den Brom

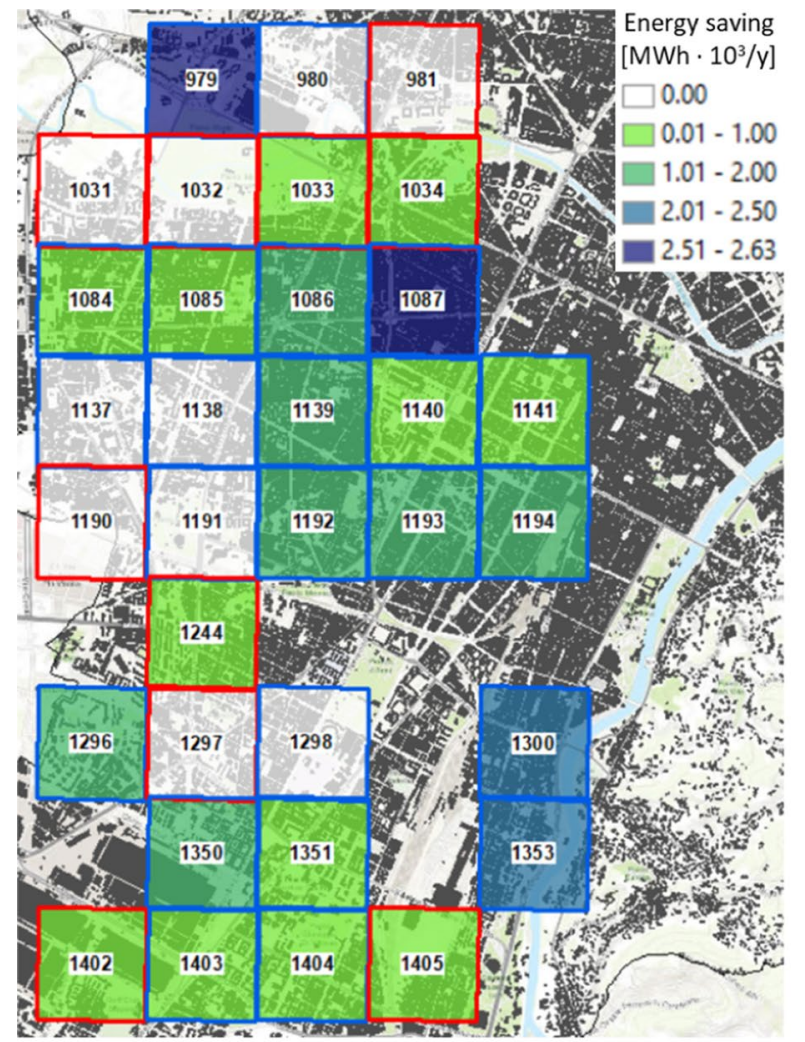

(a)

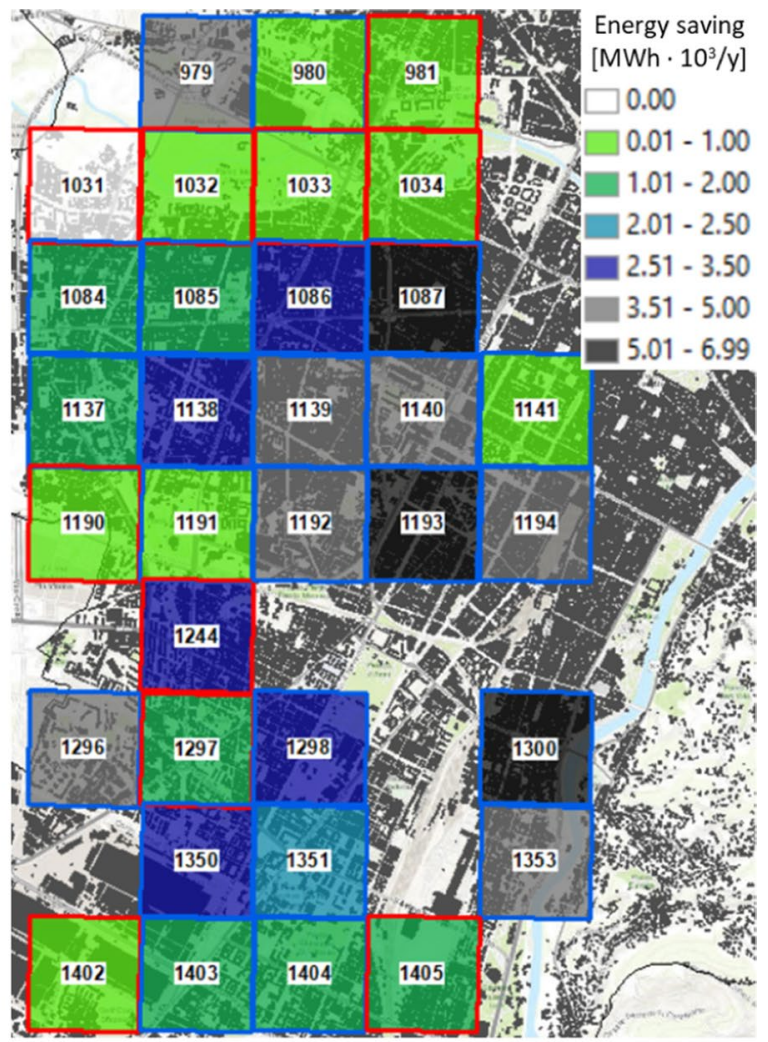

(b)

Fig. 13 Annual energy savings at a district scale after energy retrofitting strategies: a thermal insulation of the opaque envelope; b thermal insulation of the opaque envelope and window replacements 
Table 9 Costs of the retrofitting measures and the energy saving (\%) of residential flats

\begin{tabular}{llc}
\hline Retrofitting measure & Costs of retrofitting measure $\left(€ / \mathrm{m}^{2}\right)$ & $\begin{array}{l}\text { Range of } \\
\text { energy saving } \\
(\%)\end{array}$ \\
\hline $\begin{array}{l}\text { Thermal insulation of the roof } \\
\text { Thermal insulation of the slab/floor }\end{array}$ & $105^{*} € / \mathrm{m}^{2}\left(\mathrm{~m}^{2}\right.$ refers to the roof/slab/floor area $)$ & $11-25 \%$ \\
Window replacements & $890 € / \mathrm{m}^{2}$ ( $\mathrm{m}^{2}$ refers to the surface of windows $)$ & $5-7 \%$ \\
Thermal insulation of vertical walls & $92 € / \mathrm{m}^{2}\left(\mathrm{~m}^{2}\right.$ refers to the surface of walls $)$ & $11-25 \%$ \\
\hline
\end{tabular}

*The ENEA Report only indicated an average cost for the roof and slab/floor interventions

et al., 2018). If fuel prices increase, consumers with a low income tend to decrease their consumption (by changing their behaviour) more than wealthy families (Bhattacharjee \& Reichard, 2011). Since socio-economic factors affect energy consumption, urban-scale energy models will be implemented, taking into consideration the real characteristics of the population, in order to identify effective energy measures. In addition, the education level also seems to have an impact on energy savings and behaviour (O'Neill \& Chen, 2002).

The limitations of these types of models are that the necessary data are often not available, but the here presented monthly engineering models mainly simulate consumptions using open data, and it is therefore possible to apply such models easily to different cities with a sufficient degree of accuracy to be able to evaluate the distribution of

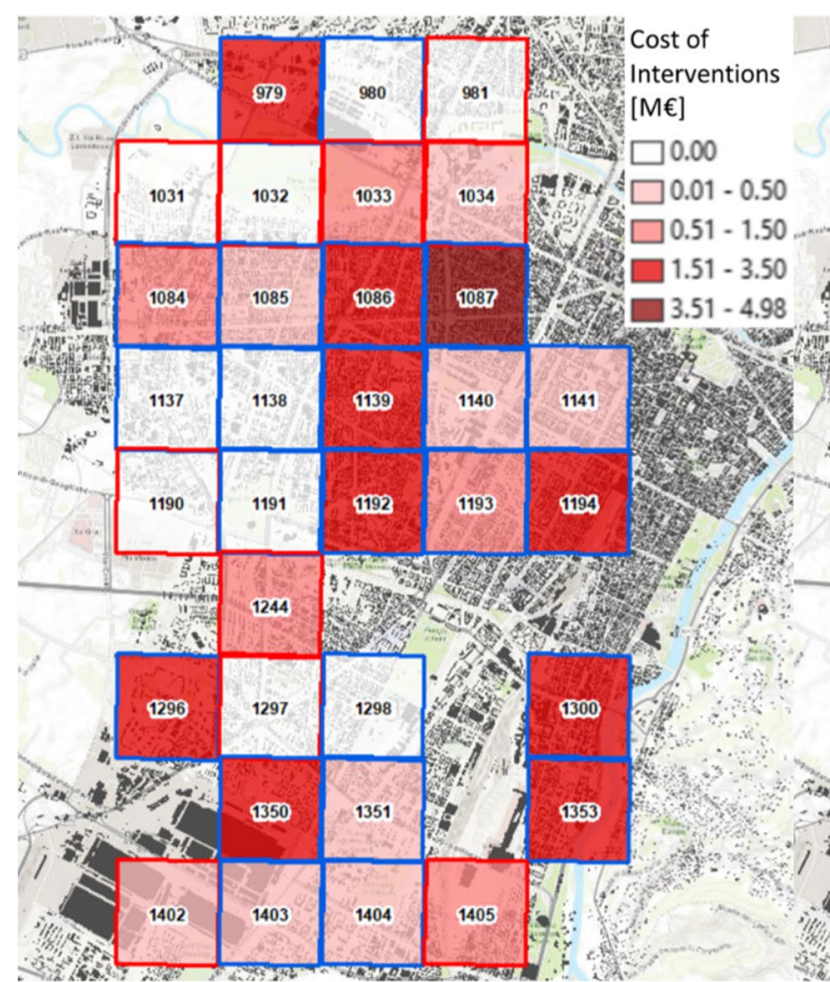

(a)

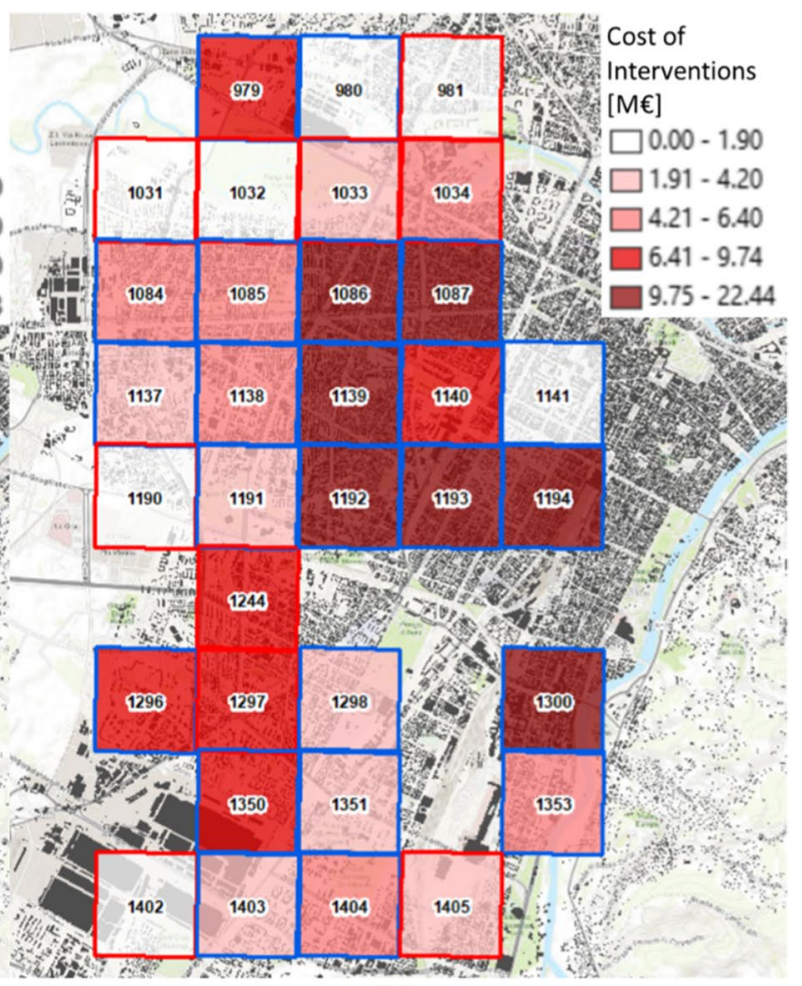

(b)

Fig. 14 Costs of the interventions at a district scale when applying energy retrofitting strategies: a thermal insulation of the opaque envelope; $\mathbf{b}$ thermal insulation of the opaque envelope and window replacements 
consumption at a city scale. Urban planners, stakeholders, and policy makers could make use of these tools to identify effective EE strategies and smart green solutions, and energy saving policies could incorporate this place-based approach. In addition, in this way, it would be possible to inform citizens about the energy consumption of their buildings, thus encouraging them to improve their EP.

\section{Conclusion}

Cities play a crucial role in the attempt to reach the European Green Deal climate targets and to become the first climate-neutral continent by 2050 . With the re-cast EPBD (2018/844/EU), the EU has strengthened the strategies identified in the residential sector, which show a significant potential to improve the energy performance of buildings by reducing GHG emissions. In order to allow an effective large-scale energy retrofitting of a building, it is necessary to know the energy performance of the existing building stock, its energy saving potential and the socio-economic characteristics of the population. Not all families can in fact afford to retrofit their dwellings, and the use of incentives and financial schemes is therefore important to support EE interventions in buildings. Both EE measures and economic benefits (i.e., incentives) are actions that must adapt to the existing context to be effective.

This work presents an input data improvement of an engineering model that simulates energy consumption at an urban scale, and an updating of the energy atlas of the city of Turin, using an EPC database of the Piedmont Region. This analysis has been conducted using 182,718 EPCs released for residential buildings from 2009 to 2015 in the city of Turin. The analysis and processing of the EPC data provided an improvement in the models results. Additionally, it also allowed to take into account the retrofit interventions already carried out and the real technical and historical constraints that limit their effective execution. Thanks to the use of EPCs as input data, it has been possible to identify the share of retrofitted buildings by distinguishing between the types of intervention for each construction period and type of building. The urban energy model was thus implemented with an improvement in the relative error of 9 to $5 \%$ of the H+DHW model and of 17 to $13 \%$ of the $\mathrm{H}$ model. Such an assessment could play a significant role in the planning of smart energy solutions for a sustainable development at a city level and for the expansion of the DHN.

The GIS platform presented in this work is not a simple web tool that allows data to be visualised at different scales, but is rather a dynamic decision-making energy tool that allows predictions to be made by changing the building, urban and/or climate variables. This is possible because this tool is based on an engineering model that simulates energy consumption, by taking into account the real urban environment. In addition, this platform can also evaluate the available renewable energy sources that meet the local energy demand and, thanks the implementation of the EPCs database, it allows to consider realistic EE scenarios.

The here presented urban energy atlas may be used to: explore energy consumption, GHG emissions and thermal comfort conditions in urban spaces; quantitatively assess energy retrofitting strategies and their impacts on the territory; promote smart green solutions (i.e., green roofs) through a new environmental energy annex of the building code, financial mechanisms and incentives; identify more effective energy policies, considering the real characteristics of the buildings, of the population and of the urban morphology. With this place-based approach, it is possible to evaluate future scenarios in which energy security, sustainability and affordability will be improved in order to attain a more resilient city. In addition, the use of a GIS tool, through the implementation of an urban platform, facilitates access to data and the spatial representation of the results.

Future work will focus on strategies to mitigate the urban heat island effect, to improve outdoor and indoor thermal comfort and to reduce energy consumptions, using, for example, smart green roof technologies. Additionally, the promotion of EE measures will be investigated using new financial instruments to facilitate the sharing of energy between condominiums and communities. As such, mixing different energy consumers, producers and prosumers will solve the issue of high-density cities.

Funding Open access funding provided by Politecnico di Torino within the CRUI-CARE Agreement.

\section{Declarations}

Conflicts of interest The authors declare that they have no conflicts of interest. 
Open Access This article is licensed under a Creative Commons Attribution 4.0 International License, which permits use, sharing, adaptation, distribution and reproduction in any medium or format, as long as you give appropriate credit to the original author(s) and the source, provide a link to the Creative Commons licence, and indicate if changes were made. The images or other third party material in this article are included in the article's Creative Commons licence, unless indicated otherwise in a credit line to the material. If material is not included in the article's Creative Commons licence and your intended use is not permitted by statutory regulation or exceeds the permitted use, you will need to obtain permission directly from the copyright holder. To view a copy of this licence, visit http://creativecommons.org/licenses/by/4.0/.

\section{References}

Abbasabadi, N., \& Ashayeri, M. (2019). Urban energy use modeling methods and tools: A review and an outlook. Building and Environment, 161, 106270. https://doi.org/ 10.1016/J.BUILDENV.2019.106270.

Ahern, C., \& Norton, B. (2020). Energy Performance Certification: Misassessment due to assuming default heat losses. Energy and Buildings, 224, 110229. https://doi.org/10. 1016/j.enbuild.2020.110229.

Alhamwi, A., Medjroubi, W., Vogt, T., \& Agert, C. (2017). GIS-based urban energy systems models and tools: Introducing a model for the optimisation of flexibilisation technologies in urban areas. Applied Energy, 191, 1-9. https:// doi.org/10.1016/j.apenergy.2017.01.048.

Ali, U., Shamsi, M. H., Bohacek, M., Hoare, C., Purcell, K., Mangina, E., \& O’Donnell, J. (2020a). A data-driven approach to optimize urban scale energy retrofit decisions for residential buildings. Applied Energy, 267, 114861. https://doi.org/10.1016/j.apenergy.2020.114861.

Ali, U., Shamsi, M. H., Bohacek, M., Purcell, K., Hoare, C., Mangina, E., \& O'Donnell, J. (2020b). A data-driven approach for multi-scale GIS-based building energy modeling for analysis, planning and support decision making. Applied Energy, 279, 115834. https://doi.org/10.1016/j. apenergy.2020.115834.

Arcipowska, A., Anagnostopoulos, F., Mariottini, F., \& Kunkel, S. (2014). Energy Performance Certificates Across the EU. A mapping of National Approaches (Building Performance Institute Europe, ed.). Retrieved from http://bpie.eu/publication/energy-performance-certificat es-across-the-eu/.

Ashfaq, A., \& Ianakiev, A. (2018). Features of fully integrated renewable energy atlas for Pakistan; wind, solar and cooling. Renewable and Sustainable Energy Reviews, 97, 14-27. https://doi.org/10.1016/J.RSER.2018.08.011.

Baldini, M., Brøgger, M., Jacobsen, H. K., \& Wittchen, K. B. (2020). Cost-effectiveness of energy efficiency improvements for a residential building stock in a Danish district heating area. Energy Efficiency, 13(8), 1737-1761. https:// doi.org/10.1007/s12053-020-09889-x.

Barrile, V., Fotia, A., Bilotta, G., \& Calabria, R. (2018). Geodatabase for the assessment of energetic potential of territory. Ingénierie Des Systèmes d'Information, 7-17. https://doi.org/10.3166/ISI.23.6.7-17.

Beerepoot, M., \& Sunikka, M. (2005). The contribution of the EC energy certificate in improving sustainability of the housing stock. Environment and Planning $b$ : Planning and Design, 32(1), 21-31. https://doi.org/10.1068/b3118.

Ben, H., \& Steemers, K. (2020). Modelling energy retrofit using household archetypes. Energy and Buildings, 224, 110224. https://doi.org/10.1016/j.enbuild.2020.110224.

Bertoldi, P., Economidou, M., Palermo, V., Boza Kiss, B., \& Todeschi, V. (2020). How to finance energy renovation of residential buildings: Review of current and emerging financing instruments in the EU. Wires Energy and Environment, 10, e384. https://doi.org/10.1002/wene.384.

Bhattacharjee, S., \& Reichard, G. (2011). Socio-Economic factors affecting individual household energy consumption: A systematic review (pp. 891-901). https://doi.org/10. 1115/ES2011-54615.

Bio Intelligence Service, Ronan, L., \& IEEP. (2013). Energy performance certificates in buildings and their impact on transaction prices and rents in selected EU countries. Final Report Prepared for European Commission, DG Energy, http://eur-lex.europa.eu/legal-content/ET/TXT/ HTML/?uri=CELEX:32010L0031\&from=EN.

Bull, R., Chang, N., \& Fleming, P. (2012). The use of building energy certificates to reduce energy consumption in European public buildings. Energy and Buildings, 50, 103110. https://doi.org/10.1016/J.ENBUILD.2012.03.032.

Caputo, P., \& Pasetti, G. (2017). Boosting the energy renovation rate of the private building stock in Italy: Policies and innovative GIS-based tools. Sustainable Cities and Society, 34, 394-404. https://doi.org/10.1016/j.scs.2017.07. 002.

Cerin, P., Hassel, L. G., \& Semenova, N. (2014). Energy Performance and housing prices. Sustainable Development, 22(6), 404-419. https://doi.org/10.1002/sd.1566.

Chalabi, Z. S., \& Bailey, B. J. (1991). Sensitivity analysis of a non-steady state model of the greenhouse microclimate. Agricultural and Forest Meteorology, 56(1), 111-127. https://doi.org/10.1016/0168-1923(91)90107-2.

Chen, Y., Hong, T., \& Piette, M. A. (2017). Automatic generation and simulation of urban building energy models based on city datasets for city-scale building retrofit analysis. Applied Energy, 205, 323-335. https://doi.org/10. 1016/J.APENERGY.2017.07.128.

Corrado, V., \& Fabrizio, E. (2007). Assessment of building cooling energy need through a quasi-steady state model: Simplified correlation for gain-loss mismatch. Energy and Buildings, 39(5), 569-579. https://doi.org/10.1016/j.enbui 1d.2006.09.012.

Cozza, S., Chambers, J., Deb, C., Scartezzini, J.-L., Schlüter, A., \& Patel, M. K. (2020a). Do energy performance certificates allow reliable predictions of actual energy consumption and savings? Learning from the Swiss national database. Energy and Buildings, 224, 110235. https://doi. org/10.1016/j.enbuild.2020.110235.

Cozza, S., Chambers, J., \& Patel, M. K. (2020b). Measuring the thermal energy performance gap of labelled residential buildings in Switzerland. Energy Policy, 137, 111085. https://doi.org/10.1016/j.enpol.2019.111085. 
Cuerda, E., Guerra-Santin, O., Sendra, J. J., \& Neila, F. J. (2020). Understanding the performance gap in energy retrofitting: Measured input data for adjusting building simulation models. Energy and Buildings, 209, 109688. https:// doi.org/10.1016/j.enbuild.2019.109688.

Dall'O', G., Galante, A., \& Torri, M. (2012). A methodology for the energy performance classification of residential building stock on an urban scale. Energy and Buildings, 48, 211-219. https://doi.org/10.1016/j.enbuild.2012.01. 034.

Davis, P. T., McCord, J. A., McCord, M., \& Haran, M. (2015). Modelling the effect of energy performance certificate rating on property value in the Belfast housing market. International Journal of Housing Markets and Analysis, 8(3), 292-317. https://doi.org/10.1108/IJHMA-09-2014-0035.

Droutsa, K. G., Kontoyiannidis, S., Dascalaki, E. G., \& Balaras, C. A. (2016). Mapping the energy performance of hellenic residential buildings from EPC (energy performance certificate) data. Energy, 98, 284-295. https://doi. org/10.1016/j.energy.2015.12.137.

Economidou, M., Todeschi, V., Bertoldi, P., D’Agostino, D., Zangheri, P., \& Castellazzi, L. (2020). Review of 50 years of EU energy efficiency policies for buildings. Energy and Buildings, 225, 110322. https://doi.org/10.1016/j.enbuild. 2020.110322.

Fabbri, K., Zuppiroli, M., \& Ambrogio, K. (2012). Heritage buildings and energy performance: Mapping with GIS tools. Energy and Buildings, 48, 137-145. https://doi.org/ 10.1016/j.enbuild.2012.01.018.

Fan, Y., \& Xia, X. (2018). Building retrofit optimization models using notch test data considering energy performance certificate compliance. Applied Energy, 228(April), 21402152. https://doi.org/10.1016/j.apenergy.2018.07.043.

Fregonara, E., Rolando, D., \& Semeraro, P. (2017). Energy performance certificates in the Turin real estate market. Journal of European Real Estate Research, 10(2), 149169. https://doi.org/10.1108/JERER-05-2016-0022.

Fregonara, E., Rolando, D., Semeraro, P., \& Vella, M. (2014). The impact of Energy Performance Certificate level on house listing prices. First evidence from Italian real estate. Aestimum, 65, 143-163. https://doi.org/10.13128/Aesti mum-15459.

Groppi, D., de Santoli, L., Cumo, F., \& Astiaso Garcia, D. (2018). A GIS-based model to assess buildings energy consumption and usable solar energy potential in urban areas. Sustainable Cities and Society, 40, 546-558. https:// doi.org/10.1016/J.SCS.2018.05.005.

Guelpa, E., Mutani, G., Todeschi, V., \& Verda, V. (2018). Reduction of $\mathrm{CO}_{2}$ emissions in urban areas through optimal expansion of existing district heating networks. Journal of Cleaner Production, 204, 117-129. https://doi.org/ 10.1016/j.jclepro.2018.08.272.

Gupta, R., \& Gregg, M. (2018). Targeting and modelling urban energy retrofits using a city-scale energy mapping approach. Journal of Cleaner Production, 174, 401-412. https://doi. org/10.1016/j.jclepro.2017.10.262.

Hardy, A., \& Glew, D. (2019). An analysis of errors in the Energy Performance certificate database. Energy Policy, 129, 1168-1178. https://doi.org/10.1016/j.enpol.2019.03. 022 .
Herrando, M., Cambra, D., Navarro, M., de la Cruz, L., Millán, G., \& Zabalza, I. (2016). Energy Performance Certification of Faculty Buildings in Spain: The gap between estimated and real energy consumption. Energy Conversion and Management, 125, 141-153. https://doi.org/10. 1016/j.enconman.2016.04.037.

Hjortling, C., Björk, F., Berg, M., \& Klintberg, T. (2017). Energy mapping of existing building stock in Sweden Analysis of data from Energy Performance Certificates. Energy and Buildings, 153, 341-355. https://doi.org/10. 1016/j.enbuild.2017.06.073.

IRENA. (2019). Global energy transformation: A roadmap to 2050. Abu Dhab.

Johansson, T., Olofsson, T., \& Mangold, M. (2017a). Development of an energy atlas for renovation of the multifamily building stock in Sweden. Applied Energy, 203, 723-736. https://doi.org/10.1016/J.APENERGY.2017.06.027.

Johansson, T., Olofsson, T., \& Mangold, M. (2017b). Development of an energy atlas for renovation of the multifamily building stock in Sweden. Applied Energy, 203(2017), 723-736. https://doi.org/10.1016/j.apenergy.2017.06.027.

Kristensen, M. H., Hedegaard, R. E., \& Petersen, S. (2018). Hierarchical calibration of archetypes for urban building energy modeling. Energy and Buildings, 175, 219-234. https://doi.org/10.1016/J.ENBUILD.2018.07.030.

Las-Heras-Casas, J., López-Ochoa, L. M., López-González, L. M., \& Paredes-Sánchez, J. P. (2018). A tool for verifying energy performance certificates and improving the knowledge of the residential sector: A case study of the Autonomous Community of Aragón (Spain). Sustainable Cities and Society, 41, 62-72. https://doi.org/10.1016/j.scs.2018. 05.016 .

Luo, X., Hong, T., \& Tang, Y.-H. (2020). Modeling thermal interactions between buildings in an urban context. Energies, 13(9), 2382. https://doi.org/10.3390/en13092382.

Martínez-Molina, A., Tort-Ausina, I., Cho, S., \& Vivancos, J.-L. (2016). Energy efficiency and thermal comfort in historic buildings: A review. Renewable and Sustainable Energy Reviews, 61, 70-85. https://doi.org/10.1016/J. RSER.2016.03.018.

Moeller, S., Weber, I., Schröder, F., Bauer, A., \& Harter, H. (2020). Apartment related energy performance gap - How to address internal heat transfers in multi-apartment buildings. Energy and Buildings, 215, 109887. https://doi.org/ 10.1016/j.enbuild.2020.109887.

Mutani, G., \& Todeschi, V. (2018). Energy resilience, vulnerability and risk in urban spaces. Journal of Sustainable Development of Energy, Water and Environment Systems, 6(4), 694-709. https://doi.org/10.13044/J.SDEWES.D6. 0211.

Mutani, G., \& Todeschi, V. (2019). An urban energy atlas and engineering model for resilient cities. International Journal of Heat and Technology, 37, 936-947. https://doi.org/ 10.18280/ijht.370402.

Mutani, G., \& Todeschi, V. (2020). Building energy modeling at neighborhood scale. Energy Efficiency. https://doi.org/ 10.1007/s12053-020-09882-4.

Mutani, G., Beltramino, B., \& Schiavone, M. (2020a). Placebased Atlas for energy communities using energy performance certificates database". IEEE Cando Conference, 
2020, 179-184. https://doi.org/10.1109/CANDO-EPE51 100.2020 .9337766$.

Mutani, G., Todeschi, V., \& Beltramino, S. (2020b). Energy consumption models at urban scale to measure energy resilience. Sustainability. https://doi.org/10.3390/su121 45678.

Nouvel, R., Zirak, M., Coors, V., \& Eicker, U. (2017). The influence of data quality on urban heating demand modeling using 3D city models. Computers, Environment and Urban Systems, 64, 68-80. https://doi.org/10.1016/j. compenvurbsys.2016.12.005.

O'Neill, B. C., \& Chen, B. S. (2002). Demographic determinants of household energy use in the United States. Рориlation and Development Review, 28, 53-88. Retrieved from http://www.jstor.org/stable/3115268.

Palma, P., Gouveia, J. P., \& Simoes, S. G. (2019). Mapping the energy performance gap of dwelling stock at high-resolution scale: Implications for thermal comfort in Portuguese households. Energy and Buildings, 190, 246-261. https:// doi.org/10.1016/j.enbuild.2019.03.002.

Papadopoulos, A. M. (2016). Forty years of regulations on the thermal performance of the building envelope in Europe: Achievements, perspectives and challenges. Energy and Buildings, 127, 942-952. https://doi.org/10.1016/J. ENBUILD.2016.06.051.

Perera, A. T. D., Coccolo, S., Scartezzini, J. L., \& Mauree, D. (2018). Quantifying the impact of urban climate by extending the boundaries of urban energy system modeling. Applied Energy, 222(December 2017), 847-860. https://doi.org/10.1016/j.apenergy.2018.04.004.

Petrović, S., \& Karlsson, K. (2016). Ringkøbing-Skjern energy atlas for analysis of heat saving potentials in building stock. Energy, 110, 166-177. https://doi.org/10.1016/J. ENERGY.2016.04.046.

Quan, S. J., Li, Q., Augenbroe, G., Brown, J., \& Yang, P.P.-J. (2015). A GIS-based energy balance modeling system for urban solar buildings. Energy Procedia, 75, 2946-2952. https://doi.org/10.1016/j.egypro.2015.07.598.

Reinhart, C., Dogan, T., Jakubiec, J., Rakha, T., \& Sang, A. (2013). Umi-an urban simulation environment for building energy use, daylighting and walkability. Proceedings of BS2013: 13th Conference of IBPSA (International Building Performance Association), 476-483. Building simulation.

Sebi, C., Nadel, S., Schlomann, B., \& Steinbach, J. (2019). Policy strategies for achieving large long-term savings from retrofitting existing buildings. Energy Efficiency, 12(1), 89-105. https://doi.org/10.1007/s12053-018-9661-5.

Semple, S., \& Jenkins, D. (2020). Variation of energy performance certificate assessments in the European Union. Energy Policy, 137, 111127. https://doi.org/10.1016/J. ENPOL.2019.111127.

Serrano, S., Ürge-Vorsatz, D., Barreneche, C., Palacios, A., \& Cabeza, L. F. (2017). Heating and cooling energy trends and drivers in Europe. Energy, 119, 425-434. https://doi. org/10.1016/J.ENERGY.2016.12.080.
Sola, A., Corchero, C., Salom, J., \& Sanmarti, M. (2018). Simulation tools to build urban-scale energy models: A review. Energies, 11(12). https://doi.org/10.3390/en111 23269.

Sola, A., Corchero, C., Salom, J., \& Sanmarti, M. (2019). Multi-domain urban-scale energy modelling tools: A review. Sustainable Cities and Society, 101872. https:// doi.org/10.1016/J.SCS.2019.101872.

Streicher, K. N., Padey, P., Parra, D., Bürer, M. C., Schneider, S., \& Patel, M. K. (2019). Analysis of space heating demand in the Swiss residential building stock: Elementbased bottom-up model of archetype buildings. Energy and Buildings, 184, 300-322. https://doi.org/10.1016/J. ENBUILD.2018.12.011.

Thomas, S., \& Rosenow, J. (2020). Drivers of increasing energy consumption in Europe and policy implications. Energy Policy, 137, 111108. https://doi.org/10.1016/j. enpol.2019.111108

Todeschi, V., Boghetti, R., Kämpf, J. H., \& Mutani, G. (2021). Evaluation of Urban-scale building energy-use models and tools-Application for the city of Fribourg, Switzerland. Sustainability, 13(4). https://doi.org/10.3390/su130 41595.

van den Brom, P., Meijer, A., \& Visscher, H. (2018). Performance gaps in energy consumption: household groups and building characteristics. Building Research \& Information, 46(1), 54-70. https://doi.org/10.1080/09613218. 2017.1312897.

van Dronkelaar, C., Dowson, M., Burman, E., Spataru, C., \& Mumovic, D. (2016). A review of the energy performance gap and its underlying causes in non-domestic buildings. Frontiers in Mechanical Engineering, 1, 17. https://doi. org/10.3389/fmech.2015.00017

Veken, J., Saelens, D., Verbeeck, G., \& Hens, H. (2004). Comparison of steady-state and dynamic building energy simulation programs. Computer Science.

Walter, E., \& Kämpf, J. H. (2015). A verification of CitySim results using the BESTEST and monitored consumption values. Proceedings of the 2nd Building Simulation Applications Conference, 215-222. http://infoscience.epfl.ch/ record/214754.

Yang, X., Hu, M., Heeren, N., Zhang, C., Verhagen, T., Tukker, A., \& Steubing, B. (2020). A combined GIS-archetype approach to model residential space heating energy: A case study for the Netherlands including validation. Applied Energy, 280, 115953. https://doi.org/10.1016/j. apenergy.2020.115953.

Zou, P. X. W., Xu, X., Sanjayan, J., \& Wang, J. (2018). Review of 10 years research on building energy performance gap: Life-cycle and stakeholder perspectives. Energy and Buildings, 178, 165-181. https://doi.org/10.1016/j.enbui 1d.2018.08.040.

Publisher's note Springer Nature remains neutral with regard to jurisdictional claims in published maps and institutional affiliations. 